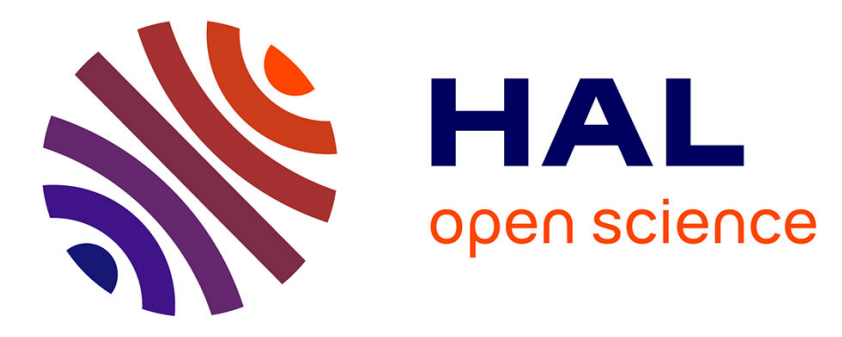

\title{
Nickel phosphonate MOF as efficient water splitting photocatalyst
}

\author{
Pablo Salcedo-Abraira, Sérgio M F Vilela, Artem Babaryk, María \\ Cabrero-Antonino, Pedro Gregorio, Fabrice Salles, Sergio Navalón, \\ Hermenegildo García, Patricia Horcajada
}

\section{To cite this version:}

Pablo Salcedo-Abraira, Sérgio M F Vilela, Artem Babaryk, María Cabrero-Antonino, Pedro Gregorio, et al.. Nickel phosphonate MOF as efficient water splitting photocatalyst. Nano Research, 2021, 14 (2), pp.450-457. 10.1007/s12274-020-3056-6 . hal-03031673

\section{HAL Id: hal-03031673 https://hal.science/hal-03031673}

Submitted on 7 Dec 2020

HAL is a multi-disciplinary open access archive for the deposit and dissemination of scientific research documents, whether they are published or not. The documents may come from teaching and research institutions in France or abroad, or from public or private research centers.
L'archive ouverte pluridisciplinaire HAL, est destinée au dépôt et à la diffusion de documents scientifiques de niveau recherche, publiés ou non, émanant des établissements d'enseignement et de recherche français ou étrangers, des laboratoires publics ou privés. 


\title{
Nickel phosphonate MOF as efficient water splitting photocatalyst
}

\author{
Pablo Salcedo-Abraira,,${ }^{1,2}$ Sérgio M. F. Vilela, ${ }^{1}$ Artem Babaryk, ${ }^{1}$ María Cabrero-Antonino, ${ }^{3}$ Pedro Gregorio, ${ }^{1}$ Fabrice Salles, ${ }^{4}$ \\ Sergio Navalón, ${ }^{3}$ Hermenegildo García, ${ }^{3}$ Patricia Horcajada ${ }^{1 *}(\varangle)$ \\ ${ }^{1}$ IMDEA Energy, Advanced Porous Materials Unit (APMU), Avda. Ramón de la Sagra 3, E-28935 Móstoles, Madrid, Spain \\ ${ }^{2}$ Departamento de Química Inorgánica I. Fac. CC. Químicas, Universidad Complutense de Madrid Avda. Complutense s/n, 28040 Madrid, Spain \\ ${ }^{3}$ Departamento de Química and Instituto de Tecnología Química (CSIC-UPV), Universitat Politècnica de València, C/Camino de Vera, s/n, 46022 \\ Valencia, Spain \\ ${ }^{4}$ Institut Charles Gerhardt Montpellier, UMR 5253 CNRS UM ENSCM, Université Montpellier, Place E. Bataillon, 34095 Montpellier Cedex 05, \\ France
}

(C) Tsinghua University Press and Springer-Verlag GmbH Germany, part of Springer Nature 2018

Received: day month year / Revised: day month year / Accepted: day month year (automatically inserted by the publisher)

\begin{abstract}
A novel microporous 2D Ni-based phosphonate metal-organic framework (MOF; denoted as IEF-13) has been successfully synthesized by a simple a green hydrothermal method and fully characterized using a large panel of experimental and computational techniques. From structural resolution from single-crystal X-ray diffraction, IEF-13 crystallizes in the triclinic space group $P$-1 based on bi-octahedra nickel nodes and a photo/electroactive tritopic phosphonate ligand. Remarkably, this material exhibits coordinatively unsaturated nickel(II) sites, free $-\mathrm{PO}_{3} \mathrm{H}_{2}$ and $-\mathrm{PO}_{3} \mathrm{H}$ acidic groups, a $\mathrm{CO}_{2}$ accessible microporosity, and an exceptional thermal and chemical stability. Further, its in-deep optoelectronic characterization evidences a photoresponse suitable for photocatalysis. In this sense, the photocatalytic activity for challenging $\mathrm{H}_{2}$ generation and overall water splitting has been pioneering evaluated for a phosphonate-MOF in absence of any co-catalyst using UV-Vis irradiation and simulated sunlight. IEF-13 is able to produce up to $2200 \mu \mathrm{mol}$ of $\mathrm{H}_{2} \cdot \mathrm{g}^{-1}$ using methanol as sacrificial agent, whereas remaining stable and allowing recycling. preserving its crystalline structure. Even more, $170 \mu \mathrm{mol}$ of $\mathrm{H}_{2} \cdot \mathrm{g}^{-1}$ were produced using IEF-13 as photocatalyst in absence of any co-catalyst in the more challenging overall water splitting, being this reaction limited by the $\mathrm{O}_{2}$ reduction. Thus, this original work opens new avenues to further optimize the photocatalytic activity of this type of multifunctional materials.
\end{abstract}

\section{KEYWORDS}

Metal-organic framework, phosphonates, photocatalysis, water splitting

\section{Introduction}

Metal-organic frameworks (MOFs) or porous coordination polymers (PCPs), combining a huge versatility and regular porosity [1-3], are promising multifunctional materials in different economically-key fields (separation, sensing, energy, biomedicine and catalysis, among others) [4-6]. While most of the reported structures are based on carboxylate and/or N-donor organic spacers; phosphonate-based MOFs (P-MOFs) are poorly explored (the ratio P-MOFs vs. carboxylate-MOFs $\approx 1: 12$; according to Web of Science). This is mainly due to the non-trivial synthetic conditions using phosphonates (e.g. low commercial availability, poor solubility) and the difficult elucidation of the resulting structures, as a consequence of the large variety of phosphonate coordination modes. Nevertheless, P-MOFs are often related with a higher structural richness and an improved thermal, chemical and mechanical stability, generally associated to a stronger coordination than that of carboxylates or azolates [7]. However, from the limited number of reported P-MOFs, only 1/3 are porous architectures (according with Web of Science), evidencing the challenge of producing porous $\mathrm{P}-\mathrm{MOF}$.

Additionally, porous P-MOFs have been mostly proposed as adsorbent in separation processes [8], being a priori also excellent candidates in less explored as catalysts due to their robustness that is an essential prerequisite in heterogeneous catalysis. In this sense, nickel, as an abundant redox metal widely proposed as photo- and/or electro-catalyst, have demonstrated good performances associated with its low cost (compared with precious metals) [9]. Sometimes used as co-catalyst, direct insertion of nickel within a porous network might enhance both its accessibility and stability, leading to an improved catalytic activity. For example, Ni(II) have been recently employed as co-catalyst, enhancing its photocatalytic activity for water splitting under UV-Vis irradiation [10].

Thus, we here present a novel robust porous P-MOF (named IEF-13; IEF stands from IMDEA Energy Framework) based on the redox active $\mathrm{Ni}^{2+}$ and the tritopic phosphonate ligand 4,6-tris[4-(phosphonomethyl)phenyl]-1,3,5-triazine ( $\left.\mathrm{H}_{6} \mathrm{ttbmp}\right)$, which posesses photo- and electro-active behavior related with the heteroatomic nature of its triazine core [11]. Note here that only one structure based on $\mathrm{Zr}$ was reported using this ligand with separation purposes [12]. In contrast with this structure, IEF-13 exhibits a 2D porous structure with coordinatively unsaturated sites (CUS), beneficial for catalysis.

Combined photo-/electro-active properties of the linker and the nickel could lead to a promising synergetic effect for photocatalysis. 2D MOFs, although poorly studied as photocatalyst when compared with 3D MOFs $[13,14]$, present many advantages in catalysis: enhanced diffusion of substrates and highly available active sites. In addition, specifically in photocatalysis [15], light penetration could be improved upon illumination of 2D MOFs due to the small size of one of their dimensions [16].

Among the most (social and economically) interesting 
photocatalyzed reactions, water splitting using sun irradiation appears as a challenging process to generate solar fuels [17]. In contrast with the important number of reports using MOFs as photocatalysts in hydrogen evolution reaction (HER) [14], only one amorphous Ti-based P-MOF has been recently studied for HER in presence of a co-catalyst [18]. However, to the best of our knowledge, no examples of crystalline P-MOFs are reported as HER catalysts. Further, in contrast to HER that requires an electron donor as sacrificial agent (e.g. methanol, triethanolamine), overall water splitting uses oxygen (coming from $\mathrm{H}_{2} \mathrm{O}$ ) as electron donor, efficiently combining both HER and oxygen evolution reaction (OER). This is, however, an energetically uphill and endothermic reaction that needs from efficient photocatalysts. From the only four reports dealing with overall water splitting using MOFs $[10,16,17,19]$, any of them is based on P-MOFs and all of them require the presence of a co-catalyst (noble or base transition metals). Thus, we here evaluate for the first time an original robust P-MOF as photocatalyst in both HER and overall water splitting in absence of any co-catalyst, obtaining similar performances than other materials that used co-catalysts [19].

In the present manuscript, we originally report the photocatalytic activity for $\mathrm{H}_{2}$ generation and overall photocatalytic water splitting of the 2D P-MOF IEF-13 in absence of any co-catalyst using visible light irradiation. Thus, this work opens new avenues to further optimize the photocatalytic activity of this type of multifunctional materials.

\section{Experimental Section}

\subsection{Reagents and Solvents}

Chemicals were readily available from commercial sources and used as received without further purification: nickel(II) nitrate hexahydrate $\left(\mathrm{Ni}\left(\mathrm{NO}_{3}\right)_{2} \cdot 6 \mathrm{H}_{2} \mathrm{O}, 98 \%\right.$, Alfa Aesar).

\subsection{Synthesis of IEF-13 - $\left[\mathrm{Ni}\left(\mathrm{H}_{4}\right.\right.$ ttbmp $\left.)\left(\mathrm{H}_{2} \mathrm{O}\right)_{2}\right] \mathrm{H}_{2} \mathrm{O}$}

A reactive mixture with a molar ratio of $2: 1$ of $\mathrm{Ni}\left(\mathrm{NO}_{3}\right)_{2} \cdot 6 \mathrm{H}_{2} \mathrm{O}$ $\left(\begin{array}{llll}0.136 & \mathrm{~g}, & 0.468 & \mathrm{mmol}\end{array}\right)$ and 2,4,6-tris[4-(phosphonomethyl)phenyl]-1,3,5-triazine

( $\mathrm{H}_{6} \mathrm{ttbmp} ; 0.134 \mathrm{~g}, 0.227 \mathrm{mmol}$ ) was prepared in $15 \mathrm{~mL}$ of distilled water. The reaction solution was placed in a $23 \mathrm{~mL}$ Teflon-lined autoclave and heated following the next program: i) heating from room temperature (RT) to $120^{\circ} \mathrm{C}$ with a $0.20^{\circ} \mathrm{C} \mathrm{min}^{-1}$ rate; ii) isothermal step at $120^{\circ} \mathrm{C}$ for $48 \mathrm{~h}$; and iii) cooling down to $30^{\circ} \mathrm{C}$ with a $0.19^{\circ} \mathrm{C} \mathrm{min}^{-1}$ rate. The resulting solid was recovered as large pale yellow single-crystals by vacuum filtration, washed with copious amount of distilled water and air-dried at RT. Yield $=40 \%$

\subsection{General Instrumentation}

Scanning electron microscopy (SEM) images were collected on a Hitachi TM-100 microscope operating at $15 \mathrm{kV}$. Powder X-ray diffraction (PXRD) patterns were collected in an Empyream PANALYTICAL diffractometer, equipped with a PIXcel3D detector and with a copper radiation source $(\mathrm{Cu} \mathrm{K} \alpha, \lambda=1.5406 \AA)$, operating at $45 \mathrm{kV}$ and $40 \mathrm{~mA}$. Fourier transformed infrared (FTIR) spectra were collected in the 4000 to $400 \mathrm{~cm}^{-1}$ range using a Thermo Nicolet 6700 FTIR with ATR accessory instrument (Thermo scientific, USA). Elemental analyses were carried out in a Flash 2000 analyzer from Thermo Scientific. Inductively coupled plasma optical emission spectroscopy (ICP-OES) analyses were done in a VARIAN VISTA AX Equipment. Thermogravimetric analyses (TGA) were carried out using a SDT Q-600 thermobalance (TA instruments). Variable-temperature powder X-ray diffraction (VTPXRD) data were collected on D8 Advance Bruker AXS $\theta-2 \theta$ diffractometer $(\mathrm{Cu} \mathrm{K} \alpha$ X-radiation, $\lambda=1.54060$ $\AA$ ), equipped with a LYNXEYE XE detector, operating at $40 \mathrm{kV}$ and $40 \mathrm{~mA}$ and an Anton Paar XRK 900 high-temperature chamber. Gasses sorption experiments were carried out in a Micromeritics TriStar II PLUS equipment. X-ray photoelectron spectra (XPS) were recorded on a SPECS spectrometer equipped with a MCD-9 detector using a monochromatic Al K $\alpha$ (hv = 1486.6 eV) X-ray source. Diffuse reflectance UV-Vis measurements were recorded in a Perkin Elmer (Lambda 19) equipped with an integrating sphere.

\subsection{Crystallographic Studies}

A plate-like crystal $\left[\mathrm{Ni}\left(\mathrm{H}_{4} \mathrm{ttbmp}\right)\left(\mathrm{H}_{2} \mathrm{O}\right)_{2}\right] \cdot \mathrm{H}_{2} \mathrm{O}$, IEF-13, was selected under optical microscope, covered with Apiezon $\mathrm{M}$ grease and attached to a Mitigen MicroLoop $\mathrm{E}^{\mathrm{TM}}$. The X-ray intensity data were measured on a Bruker D8 Venture diffractometer equipped with an air-cooled $\mathrm{I} \mu \mathrm{S} \mathrm{CuKa}$ microfocus source and Bruker Photon100 CMOS detector at total exposure time of $27.04 \mathrm{~h}$. The frames were integrated with the Bruker SAINT software package using a narrow-frame algorithm. The integration of the data using a triclinic unit cell yielded a total of 24653 reflections to a maximum $\theta$ angle of $72.44^{\circ}(0.81 \AA$ resolution $)$, of which 5683 were independent (average redundancy 4.338, completeness $=97.1 \%$, $\left.\mathrm{R}_{\mathrm{int}}=2.07 \%, \mathrm{R}_{\mathrm{sig}}=1.69 \%\right)$ and $5126(90.20 \%)$ were greater than $2 \sigma\left(F^{2}\right)$. The final cell constants of $a=10.2209(9) \AA, b=10.3011(9)$ $\AA, c=15.2914(13) \AA, \alpha=73.839(3)^{\circ}, \beta=73.519(3)^{\circ}, \gamma=$ $79.689(3)^{\circ}, V=1474.1(2) \AA^{3}$, are based upon the refinement of the XYZ-centroids of 9915 reflections above $20 \sigma(I)$ with $9.076^{\circ}<2 \theta$ $<144.5^{\circ}$. Data were corrected for absorption effects using the multi-scan method (SADABS). The ratio of minimum to maximum apparent transmission was 0.815 . The structure was solved using intrinsic phasing algorithm using SHELXT software [21] with almost complete set of atoms at $\mathrm{R}=10.9 \%$. Crystal structure refinements were performed by the full-matrix least-squares methods based on $F^{2}$ as implemented in SHELXL [22]. The crystallization water molecule was found disordered over three sites O12-O14 with refined occupancy factors $0.54(3) / 0.31(3)$ 0.21(1) without any restraints. Hydrogen atoms on carbon atoms was placed geometrically and refined in a 'riding atom' model with $U_{\text {iso }}(\mathrm{H})=1.2 U_{\text {iso }}(\mathrm{C})$. The hydrogen atoms at protonated phosphonate groups were located inspecting difference Fourier maps and their atomic positions were fixed, constraining $U_{\text {iso }}(\mathrm{H})=1.5 U_{\text {iso }}(\mathrm{O})$. The similar procedure was applied for treatment of water molecule hydrogen atoms; however, complete modelling was unsuccessful due to strong positional disorder of the latter. The final anisotropic full-matrix least-squares refinement on $F^{2}$ with 410 variables converged at $R_{1}=2.75 \%$, for the observed data and $w R_{2}=7.74 \%$ for all data. The goodness-of-fit was 1.027. The largest peak in the final difference electron density synthesis was $0.287 \mathrm{e}^{-} / \AA^{3}$ and the largest hole was $-0.337 \mathrm{e}^{-} / \AA^{3}$ with an RMS deviation of 0.050 $\mathrm{e}^{-} / \AA^{3}$.

\subsection{Computational section}

Grand Canonical Monte Carlo (GCMC) simulations were performed using a home-made code to calculate the adsorption enthalpy at low coverage (1 molecule per cell) and to determine the adsorption isotherm for each adsorbate molecule considered 
here $\left(\mathrm{CO}_{2}, \mathrm{H}_{2} \mathrm{O}\right)$ in the investigated solid dehydrated (only with the coordinate water molecules) and anhydrous (without any water molecule) structures. A multi-cell formed by $3 \times 3 \times 2$ unit cells has been used for the calculations in order to use a cut-off for Lennard Jones energy calculations equal to $12.5 \AA$.

To predict the adsorption isotherms and the enthalpy values, the equilibrium of chemical potentials between the adsorbed phase in the pores and the gaseous phase was imposed at a given temperature [23]. During these calculations, the motion of adsorbate molecules included translation, rotation, deletion and insertion randomly considered during the equilibration steps.

Different parameters (temperature, chemical potentials for adsorbate vapor and unit cell volume) were kept as fixed. Then, the interactions between adsorbate molecules and the solid were evaluated by using 12-6 Lennard Jones and electrostatic potentials and considering 3D periodic boundary conditions.

Computations were performed at $300 \mathrm{~K}$ using $10^{7}$ Monte Carlo production steps following $2 \times 10^{7}$ equilibration steps. The partial atomic charges were evaluated by electronegativity equalization procedure, while the 12-6 Lennard-Jones atomic parameters for the framework were taken from the literature (UFF force field) [24]. Water and $\mathrm{CO}_{2}$ molecules were considered as rigid and modelled by the four-site charged LJ TIP4P/2005, home-made developed and Harris and Yung models, respectively [25-27].

The parameters of the adsorbate/adsorbent $\mathrm{LJ}$ interatomic potential were then calculated using the Lorentz-Berthelot combining rule. A cutoff radius of $12 \AA$ was applied to all LJ interactions, and the long-range electrostatic interactions were handled by applying the summation Ewald technique.

\subsection{Photocurrent measurements}

Photocurrent experiments were performed using a standard three-electrode electrochemical cell using a FTO-coated glass with IEF-13 as working electrode, a platinum wire as counter electrode and a standard calomel electrode (SCE) as the reference electrode. IEF-13 was deposited on FTO-coated glass substrate by the doctor blade method using a suspension of IEF-13 (75 mg) in acetone (1 $\mathrm{mL})$ and $\alpha$-terpineol $(0.5 \mathrm{~mL})$. The employed electrolyte consisted of a dry acetonitrile solution of tetrabutylammonium hexafluorophosphate $\left(\mathrm{TB}_{4} \mathrm{PF}_{6} ; 0.1 \mathrm{M}\right)$ solution. Oxygen was removed from the cell by bubbling an Ar stream through the electrolyte. Irradiation was performed using an optical fiber connected to a Xe lamp $(300 \mathrm{~W})$. The photocurrent was measured under dark and upon illumination polarizing the working electrode at potentials from 1.6 to $-0.2 \mathrm{~V}$. Analogous experiments were performed adding to the electrolyte solution methanol $(300 \mu \mathrm{L})$.

\subsection{Photocatalytic reactions}

The photocatalytic reactions were carried out in a quartz photoreactor $(51 \mathrm{~mL})$. Different amounts of IEF-13 (i.e. 5, 10 or 15 $\mathrm{mg}$ ) were suspended in $20 \mathrm{~mL}$ of Milli-Q water or a mixture of water:methanol (3:1 in volume; $20 \mathrm{~mL})$, sonicating the system for 10 min to obtain a good dispersion. This mixture was placed in the quart reactor and the system was purged for $1 \mathrm{~h}$ under Ar flow. The suspension of IEF-13 was stirred and irradiated with a $300 \mathrm{~W}$ Xenon lamp, a solar simulator (Oriel, 1 sun) or a Xe lamp (150 W) through a Czerny-Turner monochromator (PTI model 101). The temperature of the reactor was maintained at $20{ }^{\circ} \mathrm{C}$ during all the experiments. The evolved gases were analyzed from the head space using an Agilent 490 Micro gas chromatography (GC) system
(Molsieve $5 \AA$ column, using Ar as carrier gas). Photocatalytic experiments were carried out at least in duplicate. The data points correspond to the average of the measurements and error bar corresponds to the standard deviation.

\section{Results and discussion}

\subsection{Synthesis and crystal structure description of IEF-13}

A novel Ni-based MOF (named IEF-13), based on the phosphonate ligand $\mathrm{H}_{6}$ ttbmp, was successfully isolated upon an exhaustive optimization of its reaction conditions through high-throughput hydrothermal synthesis [28]. Briefly, a reactive aqueous mixture composed of $\mathrm{Ni}\left(\mathrm{NO}_{3}\right)_{2} \cdot 6 \mathrm{H}_{2} \mathrm{O}$ and $\mathrm{H}_{6}$ ttbmp (2:12 molar ratio) was heated at $120^{\circ} \mathrm{C}$ for $48 \mathrm{~h}$ (see experimental section), leading to the 2D IEF-13 structure, formulated as $\left[\mathrm{Ni}\left(\mathrm{H}_{4} \mathrm{ttbmp}\right)\left(\mathrm{H}_{2} \mathrm{O}\right)_{2}\right] \cdot \mathrm{H}_{2} \mathrm{O}($ Fig. $\mathrm{S} 1$ in the Electronic Supplementary Material (ESM)). IEF-13 was purely prepared as large single-crystals $(\sim 300 \mu \mathrm{m}$; see SEM images in Fig. S2) suitable for its structure resolution by SCXRD.

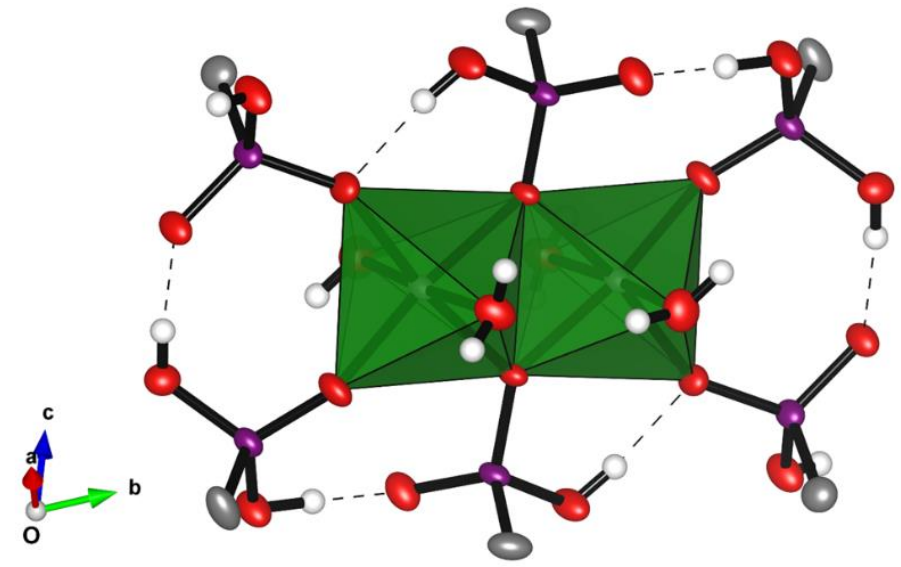

Figure 1: Schematic view of the $\mathrm{Ni}$ bi-octahedra nodes. Ni, P, C, O and $\mathrm{H}$ are represented in green, purple, grey, red and white respectively.

As revealed by SCXRD, IEF-13 crystallizes in the triclinic space group $P-1$ with polymeric nature (Table $\mathrm{S} 1$ in the ESM). Its structure is pseudo-monoclinic as can be accessed from $a \approx b$, but all attempts to refine the structure in the higher $C 2 / c$ group were unsuccessful. The metal coordination nodes consist of $\left[\mathrm{Ni}_{2} \mathrm{O}_{6}\left(\mathrm{H}_{2} \mathrm{O}\right)_{4}\right]$ bi-octahedra sharing the same $\mathrm{O} \cdots \mathrm{O}$ edge, $d=$ 2.6799(2) $\AA$ (Figure 1). This is probably due to the bridging role of two opposite phosphonate groups donating oxygen atoms of deprotonated $\mathrm{P}-\mathrm{OH}$ bonds. Terminal $\mathrm{P}=\mathrm{O}$ bonds are recognized by shorted distances, $d(\mathrm{P}=\mathrm{O})=1.4997(1)$, which are also involved into bifurcated hydrogen bonding with adjacent $\mathrm{PO}_{3} \mathrm{H}$ groups. Equatorial plane of bioctahedron is completed with four independent deprotonated phosphonate groups via monodentate coordination, while apical positions are exclusively occupied with water molecule oxygen atoms. Analysis of quadratic bond distances elongation and bond angles variance $\left(\lambda_{\mathrm{oct}}=1.0057\right.$ and $\sigma_{\text {oct }}=19.1541$ degree $^{2}$ ) confirms minimal distortions of ideal octahedral geometry (Table $\mathrm{S} 1$ ). Double deprotonated ligands alternate head-to-tail enabling $-\mathrm{CH}_{2} \mathrm{PO}_{3} \mathrm{H}$ groups to be located upwards (U) or downwards (D) with pattern -UDD-UUD-... (Fig. S3). The bottom layer of the same arranged anions is rotated on $\pi$ and shifted on $1.82 \AA$, as can be accessed from slippage of centroids of triazine rings [29]. Metal-organic layer consists of parallelogramic cyclic rings with sides $\sim 10.76 \times 12.41 \AA$ (apices coincide with triazine ring centroids and the midpoint of $\mathrm{O} \cdots \mathrm{O}$ 
edge of Ni-bioctahedra), as shown in Figure 2a. The latter occurs to be sandwiched between adjacent layers with a pitch of $3.75 \AA$ (Figure 2b). Small spatial voids between the layers host occupationally disordered guest water molecules, contacting with coordinated aqua-ligands via H-bonding. Notably, based on packing index estimation (estimated by Platon), the structure has free solvent accessible area as large as about 5\% vol. per unit cell, which is occupied by a captured water molecule.

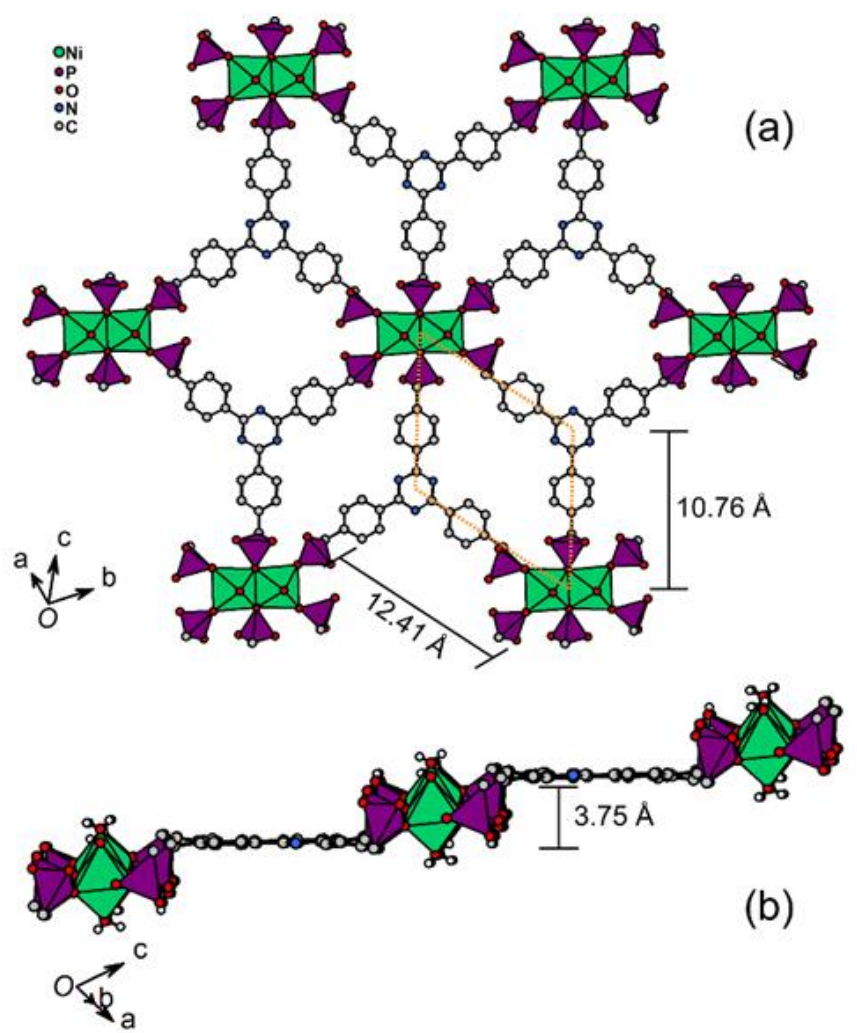

Figure 2: Flat view (a) and thick view (b) of the metal-organic layer from IEF-13. Ni, P, C, N, O and $\mathrm{H}$ are represented in green, purple, grey, blue, red and white, respectively

\subsection{Physico-chemical characterization}

The purity of the obtained polycrystalline IEF-13 sample was confirmed by a Le Bail profile fitting using PXRD (Fig. S4). When compared with the free linker, FTIR spectrum of IEF-13 (Fig. S5) shows a better definition of the two bands at $c a .3500 \mathrm{~cm}^{-1}$ corresponding to $\mathrm{v}(\mathrm{OH})$ coming from the $-\mathrm{PO}_{3} \mathrm{H}$ groups, which rotation might be more restricted than in the free state (free linker). Further, P-O bands between 988 and $928 \mathrm{~cm}^{-1}$ are also better defined and shifted to 1007 and $936 \mathrm{~cm}^{-1}$, respectively, when compared with the free ligand. Both observations suggest the coordination of the $\mathrm{Ni}$ with the $-\mathrm{PO}_{3} \mathrm{H}$ groups by the deprotonation of some acidic groups, in agreement with structural data ( 2 over 6 acidic groups deprotonated; Figure 1).

The chemical composition of the IEF-13, $\left[\mathrm{Ni}\left(\mathrm{H}_{4}\right.\right.$ ttbmp $\left.)\left(\mathrm{H}_{2} \mathrm{O}\right)_{2}\right] \cdot \mathrm{H}_{2} \mathrm{O}$, was also confirmed by elemental analysis $(\mathrm{C}, \mathrm{H}$ and $\mathrm{N}$ ) and ICP-OES ( $\mathrm{Ni}$ and $\mathrm{P})$, being the oxygen estimated by difference: Theo.(\%): C 41.05; H 4.02; N 5.98; O 27.34; P 13.23; Ni 8.36. Exp.: C 42.06; H 3.92; N 6.45; O 23.76; P 14.65; Ni 9.16. Additionally, XPS analysis of IEF-13 allows not only confirming the composition but also setting the oxidation state of the different elements (Fig. S6). Briefly, XPS C 1s shows the presence of aromatic carbons together with $\mathrm{C}-\mathrm{N}$ and $\mathrm{C}-\mathrm{P}$ bonds. Also, XPS O 1s (532.4 eV), P 2p (133.5 eV), N 1s (398.3 eV) and $\mathrm{Ni} 2 \mathrm{p}$ show the expected binding energy for the oxygen atoms in the phosphonate groups, phosphonate units, nitrogen atoms in the triazine organic unit and $\mathrm{Ni}(\mathrm{II})$, respectively.

TG analysis shows a first slight weight loss (from RT to $100^{\circ} \mathrm{C} ; 2$ wt.\%; Fig. S7), attributed to the water adsorbed on the external surface of the crystals. The following weight loss, between 100 and $250^{\circ} \mathrm{C}$, might correspond to the departure of the three water molecules of the structure ( 2 coordinated molecules and 1 crystallization water). The following progressive mass loss, starting at $500^{\circ} \mathrm{C}$, can be explained by the IEF-13 decomposition, associated with the organic ligand oxidation. The accurate quantification was hindered by the lack of identification of the final amorphous residue. Thermal stability was more precisely evaluated by VTPXRD (Fig. S8). Remarkably, IEF-13 is structurally stable up to $450^{\circ} \mathrm{C}$, leading to an amorphous phase. However, a phase transition is observed at around $150^{\circ} \mathrm{C}$, which might be associated with the departure of crystallization and coordinated water molecules, in agreement with TGA data.

Considering the potential accessible porosity of the IEF-13 framework ( $\sim 5 \%$ free vol. per unit cell, as estimated by Platon; see above), gas sorption experiments were performed using $\mathrm{N}_{2}$ and $\mathrm{CO}_{2}$ as adsorbates. IEF-13 shows no accessible porosity to $\mathrm{N}_{2}$ at $77 \mathrm{~K}$. This could be explained by simple steric hindrance: pore size (estimated from crystallographic data considering the Van der Waals radii $\sim 2.75 \AA)$ is smaller than the kinetic diameter of $\mathrm{N}_{2}(\sim$ $3.63 \AA$ ) [30]. This observation is in good agreement with the null surface area simulated for $\mathrm{N}_{2}$. In contrast, a pore volume of $c a$. $0.25 \mathrm{~cm}^{3} \cdot \mathrm{g}^{-1}$ was calculated with a probe with a radius close to zero. Considering this potential porosity, molecular simulations of the adsorption of relevant small gases (i.e. $\mathrm{CO}_{2}$, and $\mathrm{H}_{2} \mathrm{O}$ ) were carried out at $300 \mathrm{~K}$ and low pressures (up to 1 bar) in the dehydrated (considering only the presence of coordinated water) and the anhydrous (full water removal) IEF-13 structure (Fig. S9). Interestingly, $\mathrm{CO}_{2}$ could be adsorbed in the dehydrated and anhydrous IEF-13, with high enthalpy values $\left(>30 \mathrm{~kJ} \cdot \mathrm{mol}^{-1}\right.$; Fig. $\mathrm{S} 9$ ), in agreement with strong $\mathrm{CO}_{2}$-framework interactions. $\mathrm{CO}_{2}$ molecules is preferentially located close to the chemisorbed $\mathrm{H}_{2} \mathrm{O}$ molecules in the case of dehydrated structure, while interact with $\mathrm{OH}$ groups and phenyl rings in both dehydrated and anhydrous forms (see Fig. S10). Note here that $\mathrm{CO}_{2}$ could be favorably adsorbed on the CUS, although coordination cannot be considered by Monte Carlo simulation. In this line, experimentally, the solid was able to adsorb $\mathrm{CO}_{2}$ at $273 \mathrm{~K}$ (Fig. S11), reaching a higher capacity than the estimated one ( $\left.50 \mathrm{vs} .35 \mathrm{mg} \cdot \mathrm{g}^{-1}\right)$, suggesting the coordination of the $\mathrm{CO}_{2}$ to the Ni-sites. Note here that $\mathrm{CO}_{2}$ loading is comparable with the obtained ones for other MOFs under similar conditions (e.g. MIL-101(Cr), $\left.\left[\mathrm{Zn}_{3}(\mathrm{OH})(p-\mathrm{CDC})_{2.5}(\mathrm{DEF})_{4}\right]\right)$ [31]. 
Regarding water adsorption, only the dehydrated form was considered due to: i) Monte Carlo simulation using classical force field is not able to reproduce the formation of strong chemical bond (i.e. water coordination) and ii) experimentally, coordinated water removal leads to a structural phase transition, which is not taken into account in the simulation. Thus, in the dehydrated form, $5 \mathrm{mg}$ water. $\mathrm{g}^{-1}$ were adsorbed at very low $P / P_{0} \quad(\sim 0.15)$, corresponding to water molecules interacting with the coordinated water. The corresponding loading is equal to 0.2 molecule per u.c. Then, a second step can be observed at higher $P / P_{0} \quad(\sim 0.33)$, corresponding to 1 additional water molecule per u.c. (up to $12 \mathrm{mg}$ water $\left.\cdot \mathrm{g}^{-1}\right)$, followed by a last increase at $P / P_{0}=1$ of 0.3 molecules per u.c. (up to $18 \mathrm{mg}$ water $\cdot \mathrm{g}^{-1}$ ). These data are in good agreement with the free volume estimated by the crystallographic data, considering the disorder of the crystallization water with $0.2,0.3$ and 0.5 probability. It is interesting to mention the presence of two types of cages with different water affinity: one hydrophilic cavity (pore 1), formed by phosphate groups saturated with $\mathrm{OH}$ and coordinated water (in the dehydrated structure), and another cage (pore 2), more hydrophobic, formed by benzene rings. As a consequence of the presence of chemisorbed water in the pore 1 , this cage is quickly saturated at the first two adsorption steps $\left(P / P_{0}\right.$ $\sim 0.33)$ and the pore 2 is only saturated at high water pressure $\left(P / P_{0}\right.$ $\sim 1)$. The formation of specific interactions between water and IEF-13 was also evaluated by GCMC simulations (see Fig. S12). While water can strongly interact with the $\mathrm{P}-\mathrm{OH}$ present in the pore 1, water molecules interact together and not with the framework when adsorbed in the pore 2 , in agreement with its more hydrophobic character [32,33].

Once the porosity of the material was evaluated and confirmed, the chemical stability was assessed to evaluate the robustness of the material. The essays were carried out by suspending the powdered solid in a variety of organic solvents, commonly used in catalysis, and in aqueous solutions at different $\mathrm{pH}\left(1 \mathrm{mg} \cdot \mathrm{mL}^{-1}\right.$, under stirring at RT for $16 \mathrm{~h}$; see experimental section in the ESM). PXRD was used to check the structural integrity, and UV-Vis spectroscopy to quantify the linker release upon stability tests. IEF-13 is highly stable in all the tested organic solvents, keeping intact its crystalline structure (Fig. S13). In water, except for the $\mathrm{pH}=12$ (showing a complete degradation), IEF-13 exhibits a robust character, being quantitatively more stable under acidic conditions than under basic ones (from only $2 \%$ of ligand leaching at $\mathrm{pH}=1$ to $24 \%$ at $\mathrm{pH}=10$; Fig. S14). Note that the significant variation of the initial $\mathrm{pH} v s$. the final one after the stability test (e.g. from 5 to 6 and from 7 to 6 ) could be explained by the different $\mathrm{pK}_{\mathrm{a}}$ of the released polyphosphonate linker $\left(\mathrm{pK}_{\mathrm{a} 1} \sim 1\right.$ and $\left.\mathrm{pK}_{\mathrm{a} 2} \sim 6\right)$ [34]. Even more, the structural robustness of the IEF-13 was also confirmed under hydrothermal conditions at $100^{\circ} \mathrm{C}$ for $24 \mathrm{~h}$ (Fig. S15).

\subsection{Optoelectronic properties}

From structural analysis, one can anticipate that near octahedral coordination at $\left[\mathrm{Ni}(\mathrm{II}) \mathrm{O}_{6}\right]$ chromophore leads to high-spin $\left(t_{2 g}\right)^{6}\left(e_{g}\right)^{2}$ electron configuration. Consequently, the two very weak bands observed at diffuse reflectance electronic spectrum of IEF-13 (Fig. S16) were attributed to ${ }^{3} \mathrm{~A}_{2 \mathrm{~g}} \rightarrow{ }^{3} \mathrm{~T}_{1 \mathrm{~g}}$ electron transition split due to spin-orbital coupling [35]. The edge of optical absorption, estimated from Tauc plot, was of $2.83 \mathrm{eV}$, which corresponds to an indirect type of band gap. This band gap value indicates light absorption in the visible range of the solar spectrum, which makes IEF-13 interesting for photocatalytic applications.
In addition, the valence band energy was determined by XPS (Figure 3a). Remarkably, these results confirm that the IEF-13 material has the appropriate band alignment to perform the overall water splitting process (Figure 3b).
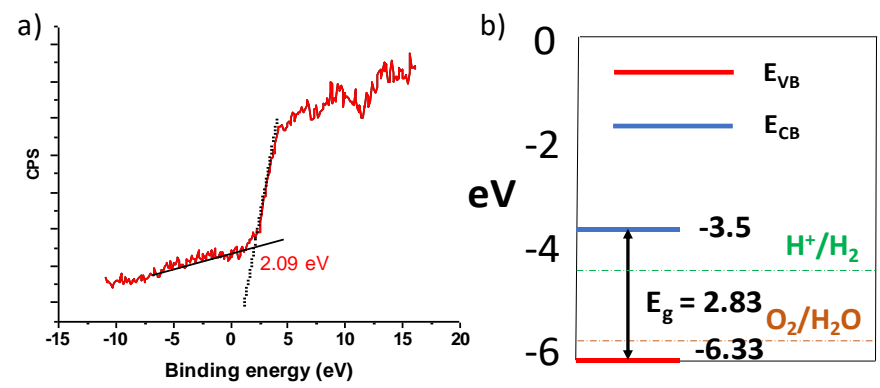

Figure 3. a) Valence band XPS and b) Band alignment for IEF-13 and positions of reduction potentials of $\mathrm{H}^{+}$to $\mathrm{H}_{2}$ and $\mathrm{O}_{2}$ to $\mathrm{H}_{2} \mathrm{O}$ in the vacuum level (Valence band $=\mathrm{VB}$; Conduction band $=\mathrm{CB}$ ).

The activity of IEF-13 as a semiconductor can be simply demonstrated by measuring the photocurrent response upon $\mathrm{Xe}$ lamp irradiation of thin films deposited on transparent conductive electrodes at increasing polarization potential in the range from -0.5 to $1.5 \mathrm{~V}$ (Figure 4). Thus, a IEF-13 photoelectrode was prepared on a clean FTO electrode by spreading this material in a mixture of terpineol:acetone following the doctor blade method that is widely used in the preparation of solar cells. The measurements were carried out in a single cell employing platinum as counter electrode and standard calomel electrode as reference using a $0.1 \mathrm{M}$ acetonitrile solution of $\mathrm{TB}_{4} \mathrm{PF}_{6}$ as electrolyte containing or not a small amount of $\mathrm{MeOH}$. A comparison of the dark current and photocurrent at different potentials is provided in Figure 4. These measurements show that illumination of the electrode increases the current at positive voltages: the larger the voltage, the higher the photocurrent. Also, in presence of the sacrificial electron donor methanol $(300 \mu \mathrm{L})$, a well-known hole quencher a, photocurrent significantly increases (> 40\%).

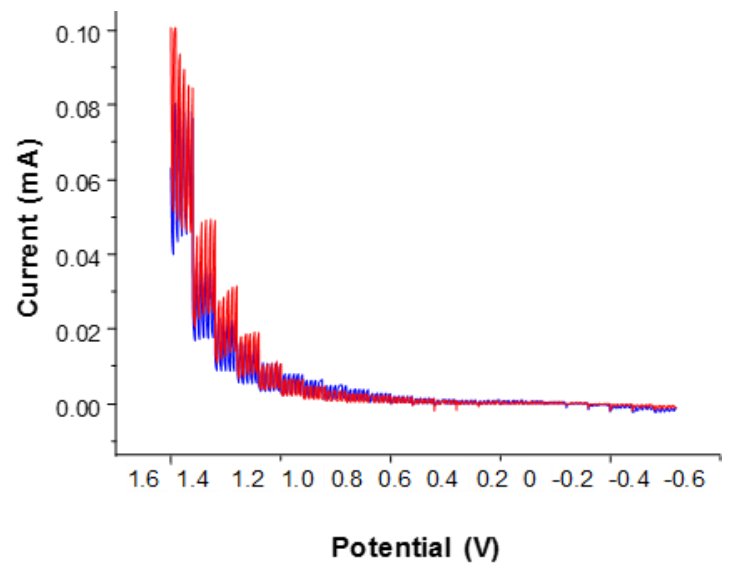

Figure 4. Photocurrent intensity $v s$. polarization potential measured for a IEF-13-FTO electrode in deaerated $0.1 \mathrm{M}$ acetonitrile solution of $\mathrm{TPAPF}_{6}$ in absence of any additive (blue line) or in presence of $\mathrm{MeOH}$ (red line) upon illumination with the output of a $300 \mathrm{~W}$ Xe lamp.

\subsection{Photocatalytic water splitting}

Considering the remarkable aqueous stability and photoresponse of IEF-13 (see above), this solid seems suitable for HER and OER photocatalysis. Consequently, IEF-13 was investigated as photocatalyst in water splitting reaction to produce solar fuels, a 
challenging process with a rising social and economic interest. Initially, the photocatalytic $\mathrm{H}_{2}$ generation was evaluated in a mixture of water and methanol upon illumination with UV-Vis or more real conditions based on simulated sunlight, reaching $c a$. a)

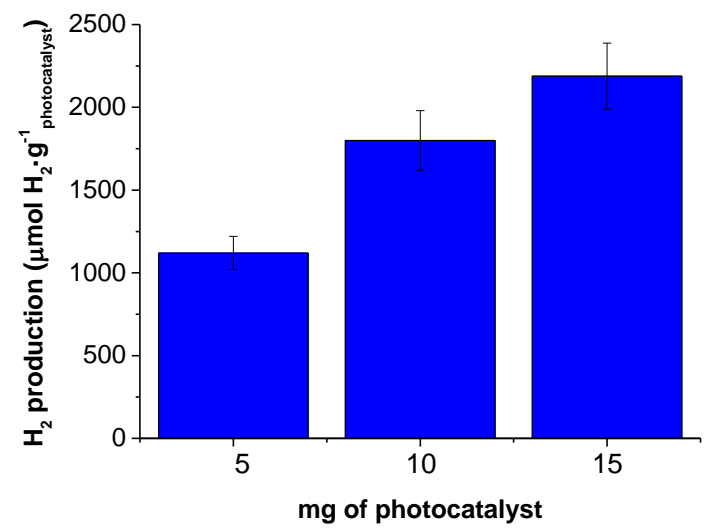

b)

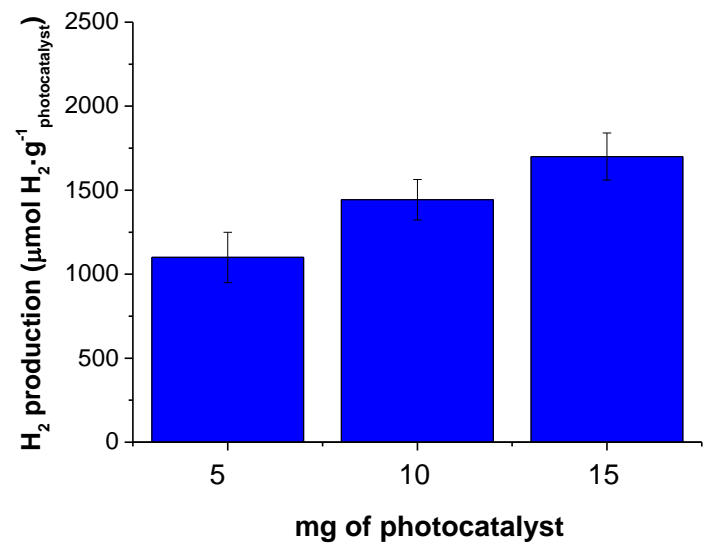

d)

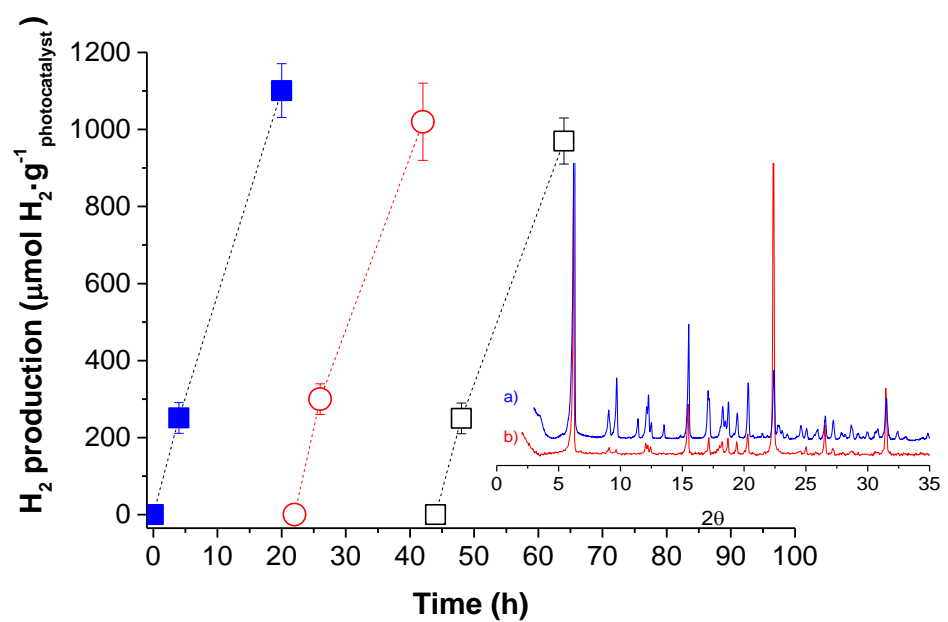

Figure 5. HER using IEF-13 as photocatalyst under UV-Vis (a) or simulated sunlight (b) as a function of the photocatalyst amount. Reusability of the IEF-13 photocatalyst under UV-Vis (c) or simulated sunlight irradiation (d). Panel d inset shows the XRD patterns of the pristine (blue) and used (red) IEF-13 solid.

2200 and $1700 \mu \mathrm{mol}$ of $\mathrm{H}_{2}$ per gram of catalyst after $22 \mathrm{~h}$, respectively (Figure 5). These values are slightly higher than those reported in analogous studies using $\mathrm{Pt}$ nanoparticles supported on the Ti aminotherepthalate MOF MIL-125(Ti)-NH2 (2200 vs. 2000 $\mu \mathrm{mol}$ of $\mathrm{H}_{2}$ per gram, respectively) [19].

Further, the amount of IEF-13 photocatalyst was optimized, observing that by increasing the photocatalyst amount, activity rises. However, this effect is not proportional to the catalyst content and is less significant when using the solar simulator. Thus, using a low concentrated catalyst (only $5 \mathrm{mg} ; 0.25 \mathrm{mg} \cdot \mathrm{g}^{-1}$ ), the solid is able to catalyze the production of around $1100 \mu \mathrm{mol}$ of $\mathrm{H}_{2}$ per gram of catalyst after $22 \mathrm{~h}$ under both UV-Vis or simulated sunlight irradiation. Moreover, IEF-13 can be reused several times, retaining more than $90 \%$ of its initial photocatalytic activity while preserving its crystalline structure during the whole photocatalytic reaction. Thus, the evidenced small deactivation may be due to the poison effect of the byproducts derived from methanol oxidation.

Finally, under similar conditions, the photocatalytic $\mathrm{H}_{2}$ generation was also carried out in pure water (in absence of methanol). Under these conditions, overall water splitting into stoichiometric amounts of $\mathrm{H}_{2}$ and $\mathrm{O}_{2}$ should occur. Figure 6 shows the temporal evolution of $\mathrm{H}_{2}$ in the overall water splitting at $20^{\circ} \mathrm{C}$.

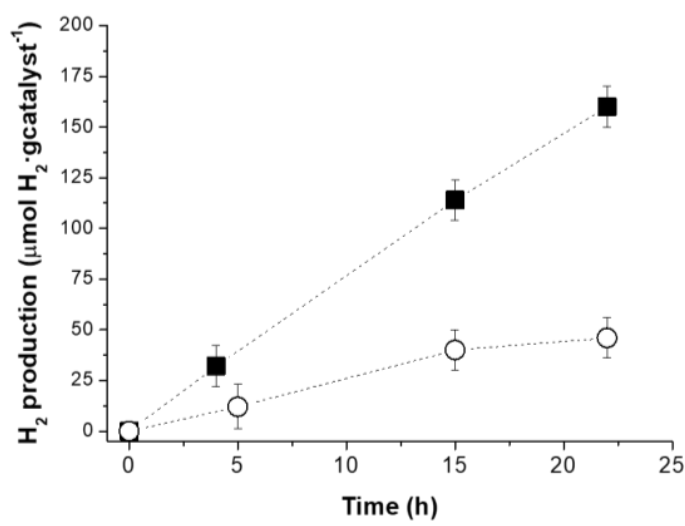

Figure 6. $\mathrm{H}_{2}$ evolution reaction using IEF-13 as photocatalyst under UV-Vis ( $\boldsymbol{\square})$ or simulated sunlight $(\bigcirc)$ in absence of any sacrificial electron donor.

The $\mathrm{H}_{2}$ production under UV-Vis or simulated sunlight irradiation was 160 and $46 \mu \mathrm{mol}$ per gram of catalyst after $22 \mathrm{~h}$, respectively. $\mathrm{H}_{2}$ productivity is here much lower, about one order of magnitude, than in presence of methanol, indicating that $\mathrm{O}_{2}$ evolution is the rate determined process (as expected). However, to put this value into context, it should be noted that the well-known Ti-MOF photocatalyst MIL-125(Ti)- $\mathrm{NH}_{2}$ gives a three-times lower $\mathrm{H}_{2}$ 
production than IEF-13 under analogous conditions, only reaching similar $\mathrm{H}_{2}$ generation when combined with $\mathrm{Ru}$ and Pt co-catalysts [19]. Although $\mathrm{O}_{2}$ evolution was also observed in the process, the amount was lower than that corresponding to the expected stoichiometry. This could indicate either that some adventitious component present in the MOF is partially acting as sacrificial electron donor or that $\mathrm{O}_{2}$ is adsorbed or reacts with some species of the system.

\section{Conclusions}

A novel microporous 2D Ni-based P-MOF (denoted as IEF-13) has been successfully synthesized by a simple a green hydrothermal method. This solid, exhibiting nickel(II) CUS as well as free $-\mathrm{PO}_{3} \mathrm{H}_{2}$ and $-\mathrm{PO}_{3} \mathrm{H}$ acidic groups, demonstrates an exceptional thermal and chemical robustness, even under aggressive conditions.

IEF-13 exhibits photocurrent whose intensity increases upon increasing the polarization voltage in the positive region and with the presence of methanol, in agreement with its semiconductor nature. This material is active as photocatalyst for HER and overall water splitting in the absence of co-catalyst. Therefore, the present results open a new area for the development of $2 \mathrm{D}$ P-MOFs as photocatalysts for solar fuels production.

\section{Acknowledgements}

This work was supported by Raphuel project (ENE2016-79608-C2-1-R, MINECO-AEI/FEDER, UE), and the Ramón Areces Foundation project H+MOFs. PH acknowledges the Spanish Ramón y Cajal Programme (2014-15039). S.N. thanks financial support by the Fundación Ramón Areces (XVIII Concurso Nacional para la Adjudicación de Ayudas a la Investigación en Ciencias de la Vida y de la Materia, 2016), Ministerio de Ciencia, Innovación y Universidades RTI2018-099482-A-I00 project and Generalitat Valenciana grupos de investigación consolidables 2019 (AICO/2019/214) project. H.G thanks financial support to the Spanish Ministry of Science and Innovation (Severo Ochoa and RTI2018-098237-CO21) and Generalitat Valenciana (Prometeo2017/083).

Electronic Supplementary Material: Supplementary material (Crystallographic information, PXRD, FTIR, TGA, XPS, VTPXRD, diffuse reflectance spectroscopy measurements, SEM images, molecular simulations, $\mathrm{CO}_{2}$ isotherm and stability tests) is available in the online version of this article at http://dx.doi.org/10.1007/s12274-********** (automatically inserted by the publisher).

\section{References}

[1] Ferey, G.; Mellot-Draznieks, C.; Serre, C.; Millange, F.; Dutour, J.; Surblé, S.; Margiolaki, I. A Chromium Terephthalate-Based Solid with Unusually Large Pore Volumes and Surface Area. Science, 2005, 309, 2040-2042.

[2] Furukawa, H.; Ko, N.; Go, Y.B.; Aratani, N.; Choi, S.B.; Choi, E.; Yazaydin, A.O.; Snurr, R.Q.; O'Keeffe, M.; Kim, J.; Yaghi, O.M. Ultrahigh Porosity in Metal-Organic Frameworks. Science, 2010, 329, 424-428.

[3] Farha, O.K.; Eryazici, I.; Jeong, N.C.; Hauser, B.G.; Wilmer, C.E.; Sarjeant, A.A.; Snurr, R.Q.; Nguyen, S.T.; Yazaydın, A.Ö.; Hupp, J.T.
Metal-Organic Framework Materials with Ultrahigh Surface Areas: Is the Sky the Limit? J. Am. Chem. Soc., 2012, 134, 15016-15021.

[4] Themed Issues: Metal-Organic Frameworks. Chem. Soc. Rev., 2009, 1201; Chem. Rev., 2012, 112; Chem. Soc. Rev., 2014, 5415.

[5] Suh, M.P.; Park, H.J.; Prasad, T.K.; Lim, D.-W. Hydrogen Storage in Metal-Organic Frameworks. Chem. Rev., 2011, 112, 782-835.

[6] Ryder, M.R.; Tan, J.-C. Nanoporous Metal Organic Framework Materials for Smart Applications. Mater. Sci. Technol., 2014, 30, 1598-1612.

Gagnon, K.J.; Perry, H.P.; Clearfield, A. Conventional and Unconventional Metal-Organic Frameworks Based on Phosphonate Ligands: MOFs and UMOFs. Chem. Rev., 2012, 112, 1034-1054.

[8] Shearan, S.J.I.; Stock, N.; Emmerling, F.; Demel, J.; Wright, P.A.; Demadis, K.D.; Vassaki, M.; Costantino, F.; Vivani, R.; Sallard, S.; Salcedo, I.R.; Cabeza, A.; Taddei, M. New Directions in Metal Phosphonate and Phosphinate Chemistry. Crystals, 2019, 9, 270.

[9] De, S.; Zhang, J.; Luque, R.; Yan, N. Ni-Based Bimetallic Heterogeneous Catalysts for Energy and Environmental Applications. Energy and Environmental Science, 2016, 9, 3314-3347.

[10] An, Y.; Liu, Y.; An, P.; Dong, J.; Xu, B.; Dai, Y.; Qin, X.; Zhang, X.; Whangbo, M.-H.; Huang, B. Ni II Coordination to an Al-Based Metal-Organic Framework Made from 2-Aminoterephthalate for Photocatalytic Overall Water Splitting. Angew. Chemie Int. Ed., 2017, 56, 3036-3040.

[11] Chen, H.F.; Yang, S.J.; Tsai, Z.H.; Hung, W.Y.; Wang, T.C.; Wong, K.T. 1,3,5-Triazine Derivatives as New Electron Transport-Type Host Materials for Highly Efficient Green Phosphorescent OLEDs. $J$. Mater. Chem., 2009, 19, 8112-8118.

[12] Taddei, M.; Costantino, F.; Marmottini, F.; Comotti, A.; Sozzani, P.; Vivani, R. The First Route to Highly Stable Crystalline Microporous Zirconium Phosphonate Metal-Organic Frameworks. Chem. Commun., 2014, 50, 14831-14834.

[13] Dhakshinamoorthy, A.; Asiri, A.M.; García, H. Metal-Organic Framework (MOF) Compounds: Photocatalysts for Redox Reactions and Solar Fuel Production. Angew. Chemie Int. Ed., 2016, 55, 5414-5445.

[14] Shi, Y.; Yang, A.F.; Cao, C.S.; Zhao, B. Applications of MOFs: Recent Advances in Photocatalytic Hydrogen Production from Water. Coordination Chemistry Reviews, 2019, 390, 50-75.

[15] Dhakshinamoorthy, A.; Asiri, A.M.; Garcia, H. 2D Metal-Organic Frameworks as Multifunctional Materials in Heterogeneous Catalysis and Electro/Photocatalysis. Adv. Mater, 2019, 31, 1900617.

[16] Carbonell, E.; Ramiro-Manzano, F.; Rodríguez, I.; Corma, A.; Meseguer, F.; García, H. Enhancement of $\mathrm{TiO} 2$ Photocatalytic Activity by Structuring the Photocatalyst Film as Photonic Sponge. Photochem. Photobiol. Sci., 2008, 7, 931-935.

[17] Abdin, Z.; Zafaranloo, A.; Rafiee, A.; Mérida, W.; Lipiński, W.; Khalilpour, K.R. Hydrogen as an Energy Vector. Renewable and Sustainable Energy Reviews, 2020, 120, 109620.

[18] Li, H.; Sun, Y.; Yuan, Z.-Y.; Zhu, Y.-P.; Ma, T.-Y. Titanium Phosphonate Based Metal-Organic Frameworks with Hierarchical Porosity for Enhanced Photocatalytic Hydrogen Evolution. Angew. Chemie, 2018, 130, 3276-3281.

[19] Remiro-Buenamañana, S.; Cabrero-Antonino, M.; Martínez-Guanter, M.; Álvaro, M.; Navalón, S.; García, H. Influence of Co-Catalysts on the Photocatalytic Activity of MIL-125(Ti)-NH2 in the Overall Water Splitting. Appl. Catal. B Environ., 2019, 254, 677-684.

[20] Fiaz, M.; Athar, M. Modification of MIL-125(Ti) by Incorporating Various Transition Metal Oxide Nanoparticles for Enhanced Photocurrent during Hydrogen and Oxygen Evolution Reactions. 
ChemistrySelect, 2019, 4, 8508-8515.

[21] Sheldrick, G.M. SHELXT - Integrated Space-Group and Crystal-Structure Determination. Acta Crystallogr. Sect. A Found. Crystallogr., 2015, 71, 3-8.

[22] Sheldrick, G.M. Crystal Structure Refinement with SHELXL. Acta Crystallogr. Sect. C Struct. Chem., 2015, 71, 3-8.

[23] Frenkel, D.; Smit, B. Understanding Molecular Simulation (Computational Science Series, Vol 1); Academic Press, 2001.

[24] Rappe, A.K.; Casewit, C.J.; Colwell, K.S.; Goddard, W.A.; Skiff, W.M. UFF, a Full Periodic Table Force Field for Molecular Mechanics and Molecular Dynamics Simulations. J. Am. Chem. Soc., 1992, 114, 10024-10035.

[25] Abascal, J.L.F.; Vega, C. A General Purpose Model for the Condensed Phases of Water: TIP4P/2005. J. Chem. Phys., 2005, 123, 234505.

[26] Salles, F.; Kolokolov, D.I.; Jobic, H.; Maurin, G.; Llewellyn, P.L.; Devic, T.; Serre, C.; Ferey, G. Adsorption and Diffusion of $\mathrm{H}_{2}$ in the MOF Type Systems MIL-47(V) and MIL-53(Cr): A Combination of Microcalorimetry and QENS Experiments with Molecular Simulations. J. Phys. Chem. C, 2009, 113, 7802-7812.

[27] Harris, J.G; Yung, K.H. Carbon Dioxide's Liquid-Vapor Coexistence Curve And Critical Properties as Predicted by a Simple Molecular Model. J. Phys. Chem., 1995, 99, 12021-12024.

[28] Stock, N. High-Throughput Investigations Employing Solvothermal Syntheses. Microporous Mesoporous Mater, 2010, 129, 287-295.

[29] Spek, A.L. Structure Validation in Chemical Crystallography. Acta
Crystallogr. Sect. D Biol. Crystallogr., 2009, 65, 148-155.

[30] Houston Frost, †; Tina Düren, + and; Randall Q. Snurr*, †. Effects of Surface Area, Free Volume, and Heat of Adsorption on Hydrogen Uptake in Metal-Organic Frameworks. 2006.

[31] Chen, C.; Lee, Y.-R.; Ahn, W.-S. CO $\langle\mathrm{SUB}>2</ \mathrm{SUB}>$ Adsorption Over Metal-Organic Frameworks: A Mini Review. J. Nanosci. Nanotechnol., 2016, 16, 4291-4301.

[32] Boudjema, L.; Long, J.; Salles, F.; Larionova, J.; Guari, Y.; Trens, P. A Switch in the Hydrophobic/Hydrophilic Gas-Adsorption Character of Prussian Blue Analogues: An Affinity Control for Smart Gas Sorption. Chem. - A Eur. J., 2018, 25, chem.201804730.

[33] Salles, F.; Bourrelly, S.; Jobic, H.; Devic, T.; Guillerm, V.; Llewellyn, P.; Serre, C.; Ferey, G; Maurin, G. Molecular Insight into the Adsorption and Diffusion of Water in the Versatile Hydrophilic/Hydrophobic Flexible MIL-53(Cr) MOF. J. Phys. Chem. C, 2011, 115, 10764-10776.

[34] Freedman, L.D.; Doak, G.O. The Preparation And Properties Of Phosphonic Acids. Chem. Rev., 1957, 57, 479-523.

[35] Wilkinson, G.; Gillard, R.D.; McCleverty, J.A. Comprehensive Coordination Chemistry: The Synthesis, Reactions, Properties \& Applications of Coordination Compounds; Pergamon Press, 1987. 


\title{
Electronic Supplementary Material
}

\section{Novel Nickel-Triazine MOF as efficient water splitting photocatalyst}

\author{
Pablo Salcedo-Abraira,,${ }^{1,2}$ Sérgio M. F. Vilela, ${ }^{1}$ Artem Babaryk, ${ }^{1}$ María Cabrero-Antonino, ${ }^{3}$ Pedro Gregorio, ${ }^{1}$ Fabrice Salles, ${ }^{4}$ \\ Sergio Navalón, ${ }^{3}$ Hermenegildo García, ${ }^{3}$ Patricia Horcajada ${ }^{1 *}(\triangle)$ \\ ${ }^{1}$ IMDEA Energy Advanced Porous Materials Unit (APMU), Avda. Ramón de la Sagra 3, E-28935 Móstoles, Madrid, Spain \\ ${ }^{2}$ Departamento de Química Inorgánica I. Fac. CC. Químicas, Universidad Complutense de Madrid Avda. Complutense s/n, 28040 Madrid, Spain \\ ${ }^{3}$ Departamento de Química and Instituto de Tecnología Química (CSIC-UPV), Universitat Politècnica de València, C/Camino de Vera, s/n, 46022 \\ Valencia, Spain \\ ${ }^{4}$ Institut Charles Gerhardt Montpellier, UMR 5253 CNRS UM ENSCM, Université Montpellier, Place E. Bataillon, 34095 Montpellier Cedex 05, \\ France
}

Supporting information to DOI 10.1007/s12274-********* (automatically inserted by the publisher)

\section{EXPERIMENTAL SECTION}

For the routine PXRD the conditions were from 3 to $35^{\circ}(2 \theta)$ using a step size of $0.013^{\circ}$ and $39.525 \mathrm{~s}$ per step in continuous mode with knife and with soller slits of $0.04 \mathrm{rad}$. For the Le Bail fitting the conditions were from 3 to $120^{\circ}(2 \theta)$ using a step size of $0.013^{\circ}$ and $200 \mathrm{~s}$ per step in continuous mode without knife and with soller slits of $0.02 \mathrm{rad}$ ).

The TGA analysis were carried out under airflow $\left(100 \mathrm{~mL} \mathrm{~min}^{-1}\right)$ with a heating rate of $5{ }^{0} \mathrm{C} \mathrm{min}^{-1}$ between room temperature and $800{ }^{\circ} \mathrm{C}$.

VTPXRD intensity data were collected under a continuous compressed air flow $\left(10 \mathrm{~mL} \mathrm{~min}^{-1}\right)$ in the step mode $\left(0.03^{\circ} 2 \theta, 1 \mathrm{~s}\right.$ per step) in the range ca. $4 \leqslant 2 \theta^{\circ} \leqslant 25$ between 30 and $800{ }^{\circ} \mathrm{C}$, in intervals of ranging from 10 to $50{ }^{\circ} \mathrm{C}$. The heating ramp used was $5^{\circ} \mathrm{C} \cdot \mathrm{min}^{-1}$.

$\mathrm{N}_{2}$ sorption experiment was carried out at $77 \mathrm{~K}$ and the sample was outgassed at $50{ }^{\circ} \mathrm{C}$ during 3 hours in primary vacuum. $\mathrm{CO}_{2}$ sorption experiment was carried out at $273 \mathrm{~K}$ and the sample was outgassed at $50{ }^{\circ} \mathrm{C}$ during 3 hours and at $80{ }^{\circ} \mathrm{C}$ during 1 hour in primary vacuum.

The stability test at room temperature were carried out by suspending $20 \mathrm{mg}$ of IEF-13 in $20 \mathrm{~mL}$ of each solution. The initial $\mathrm{pH}$ of the aqueous samples was fixed with $\mathrm{HCl}(\mathrm{pH}$ of 1 and 3) and with $\mathrm{NaOH}(\mathrm{pH}$ of 7.5, 10.5 and 12) solutions. The suspended solids were kept in sealed vials under stirring during $16 \mathrm{~h}$ (one night). After that, the samples were recovered by filtration.

Stability test in hydrothermal conditions were done by suspending $15 \mathrm{mg}$ in $1.5 \mathrm{~mL}$ of water in a sealed vial and heated at $50{ }^{\circ} \mathrm{C}$ and $100{ }^{\circ} \mathrm{C}$ during $16 \mathrm{~h}$ (one night). After that, the samples were recovered by centrifugation.

To check the crystallinity of the samples, routine PXRD were carried out of each sample.

The quantification of the released linker was made by measuring the UV-Vis absorbance at $291 \mathrm{~nm}$ of each aqueous solution after the filtration, and after interpolating the obtained absorbance in a calibration curve prepared using the Lambert-beer law. 


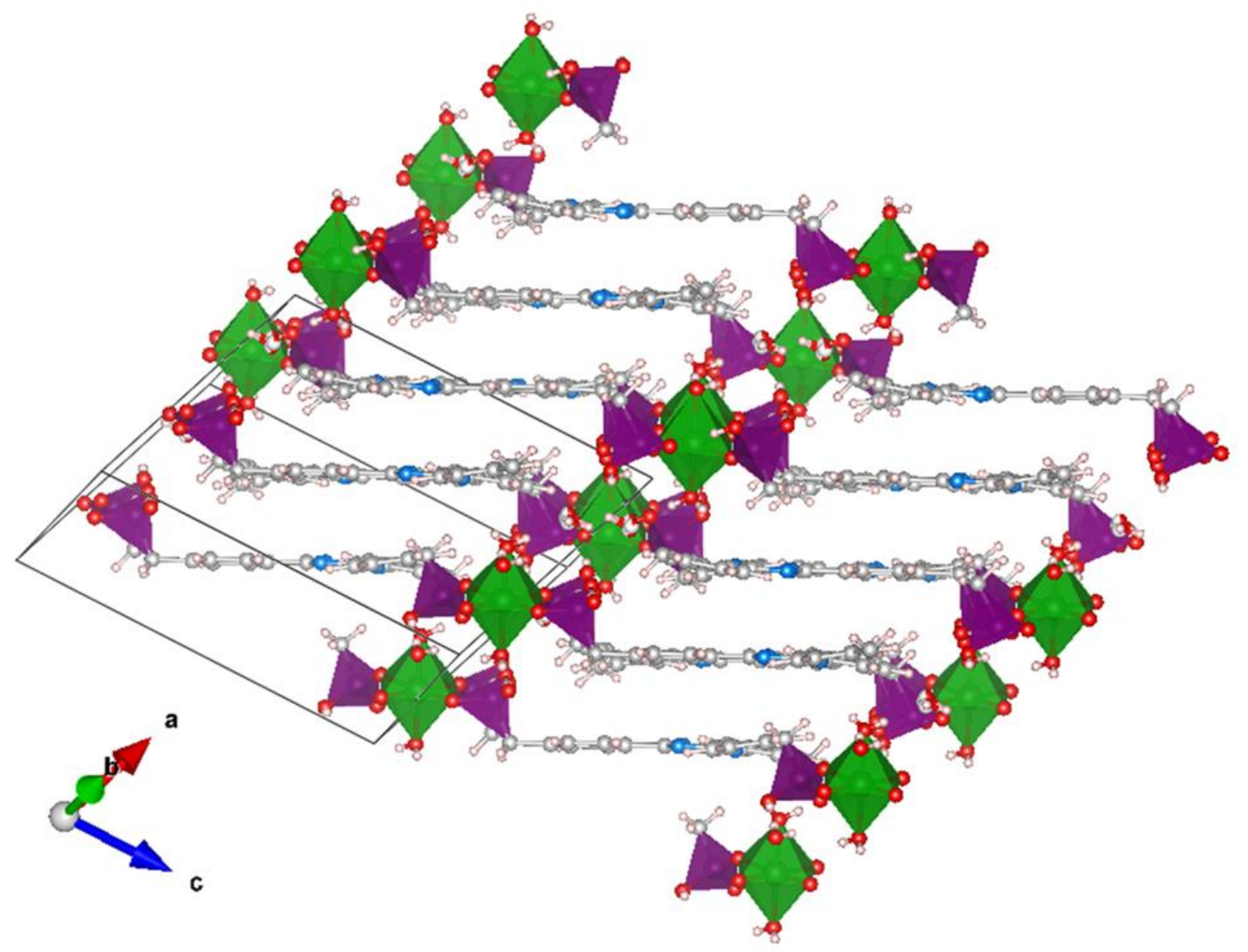

Fig. S1: Crystalline structure of the IEF-13. Ni, P, C, N, O and H are represented in green, purple, grey, blue, red and white respectively.
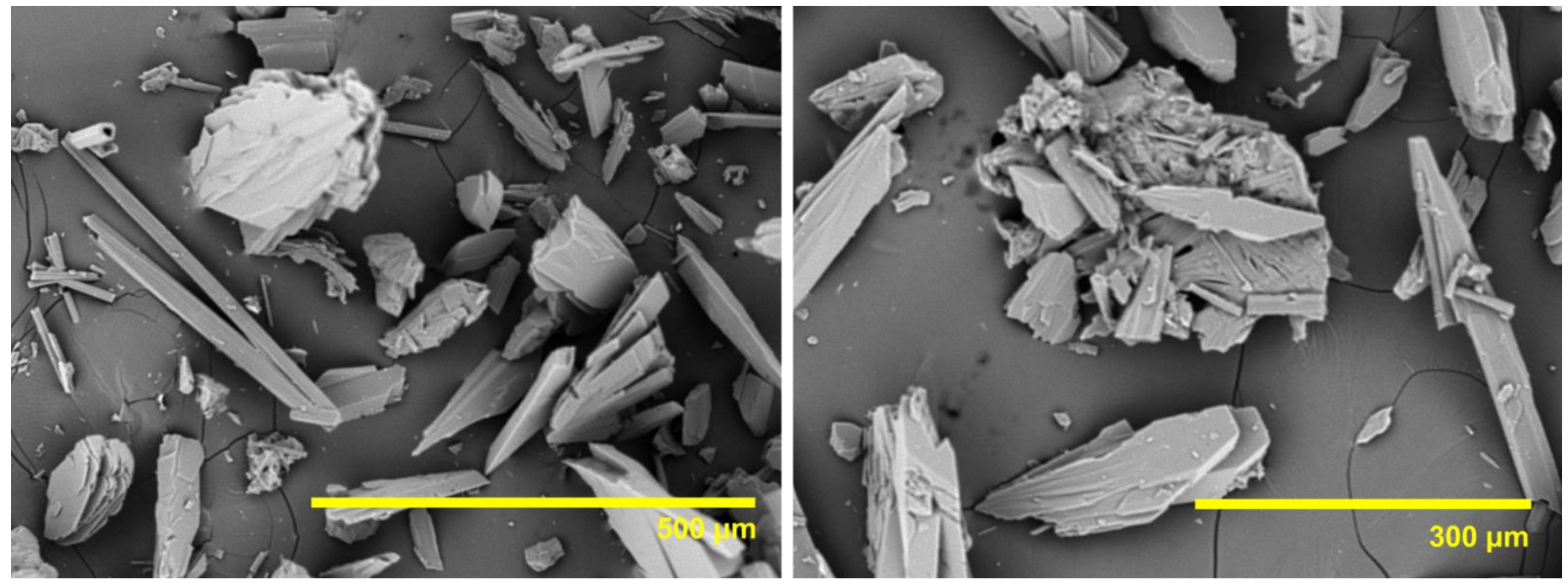

Fig. S2: SEM images of the IEF-13 material. 
Table S1. Summary of relevant crystallographic information.

\begin{tabular}{|c|c|}
\hline Chemical formula & $\mathrm{C}_{24} \mathrm{H}_{27} \mathrm{~N}_{3} \mathrm{NiO}_{12.06} \mathrm{P}_{3}$ \\
\hline Mr & 702.33 \\
\hline Crystal system, space group & Triclinic, $P-1$ \\
\hline$a, b, c(\AA)$ & 10.2209(9), 10.3011(9),15.2914(13) \\
\hline$\alpha, \beta, \gamma$ & 73.839(3), 73.519(3), 79.689(3) \\
\hline$V\left(\AA^{3}\right)$ & $1474.1(2)$ \\
\hline Z & 2 \\
\hline$\rho_{\text {calc }}\left(\mathrm{g} \mathrm{cm}^{-3}\right)$ & 1.582 \\
\hline$\mu_{\text {CuKa }}\left(\mathrm{mm}^{-1}\right)$ & 3.089 \\
\hline$F(000)$ & 723 \\
\hline Crystal size $(\mathrm{mm})$ & $0.08 \times 0.08 \times 0.20$ \\
\hline$T_{\min }, T_{\max }$ & $0.6145,0.7536$ \\
\hline Data collection temperature $(\mathrm{K})$ & 293 \\
\hline Radiation, $\lambda(\AA)$ & CuKa, 1.54178 \\
\hline$\theta_{\min }, \theta_{\max }\left({ }^{\circ}\right)$ & $4.5,72.4$ \\
\hline$h_{\min }, h_{\max }$ & $-12,12$ \\
\hline$k_{\min }, k_{\max }$ & $-12,12$ \\
\hline$I_{\min }, I_{\max }$ & $-18,18$ \\
\hline $\begin{array}{l}\text { No. of measured, unique and observed }[I \geq 2 \sigma(I)] \\
\text { reflections }\end{array}$ & $24653,5683,5126$ \\
\hline$R_{\text {int }}$ & 0.021 \\
\hline No. of reflections, No. of paratemters & 5683,410 \\
\hline$R\left[F^{2}>2 \sigma\left(F^{2}\right)\right], w R\left(F^{2}\right), S$ & $0.028,0.077,1.03$ \\
\hline$\Delta \sigma_{\max ^{-1}}$ & 0 \\
\hline$\rho_{\min }, \rho_{\max }\left(\mathrm{e} \AA^{-3}\right)$ & $-0.34,0.29$ \\
\hline
\end{tabular}




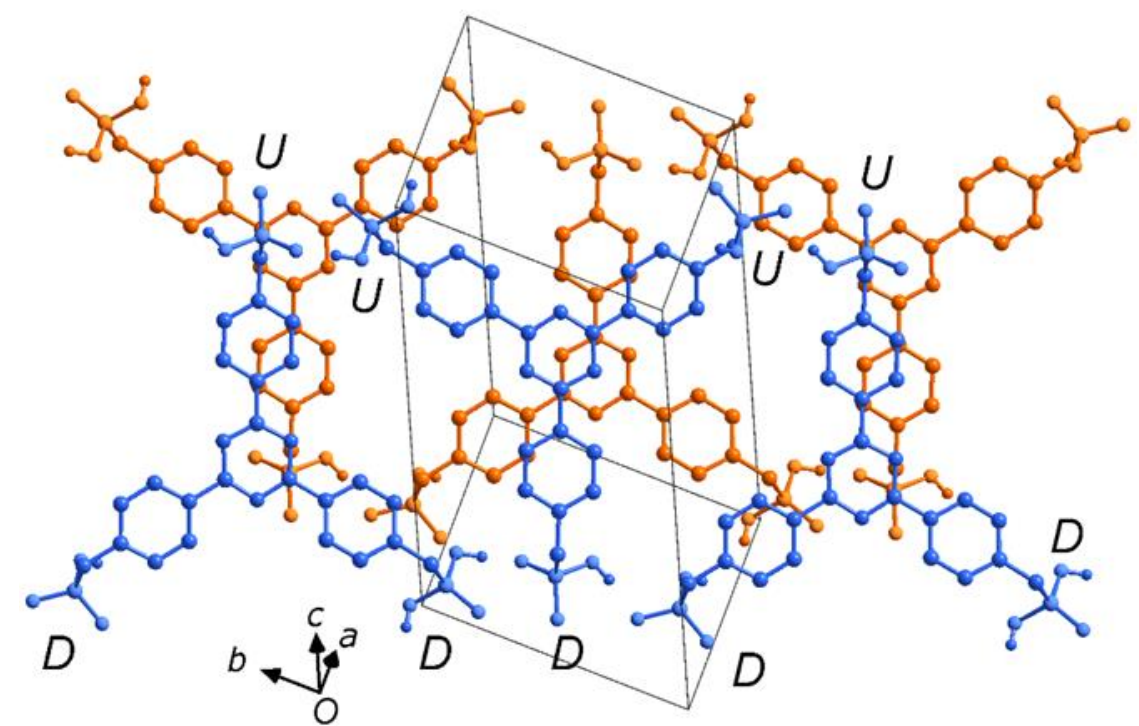

Fig. S3: Schematic view of the stacking of the linker layers in the IEF-13 material.
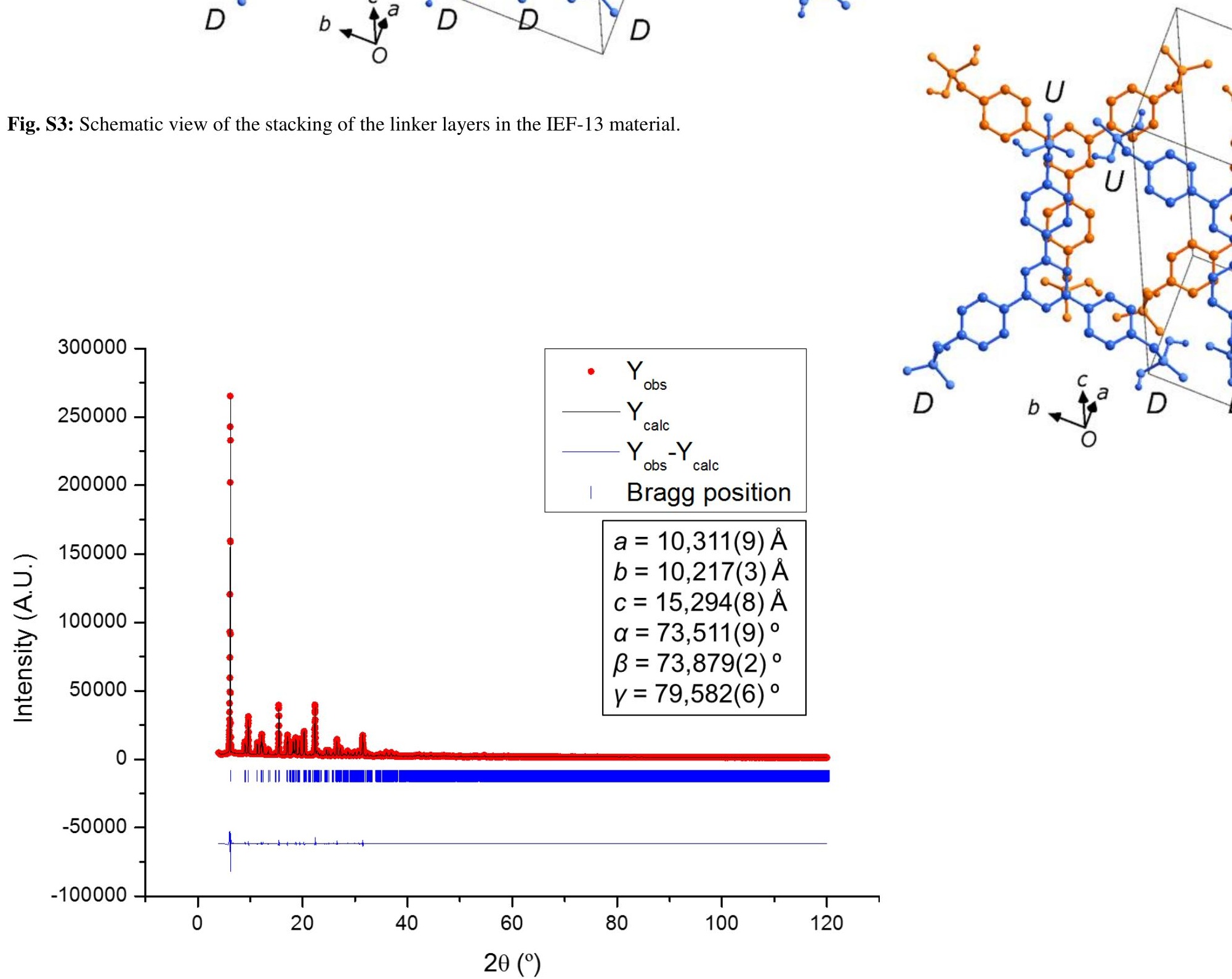

Fig. S4: Le Bail profile fitting of IEF-13. 


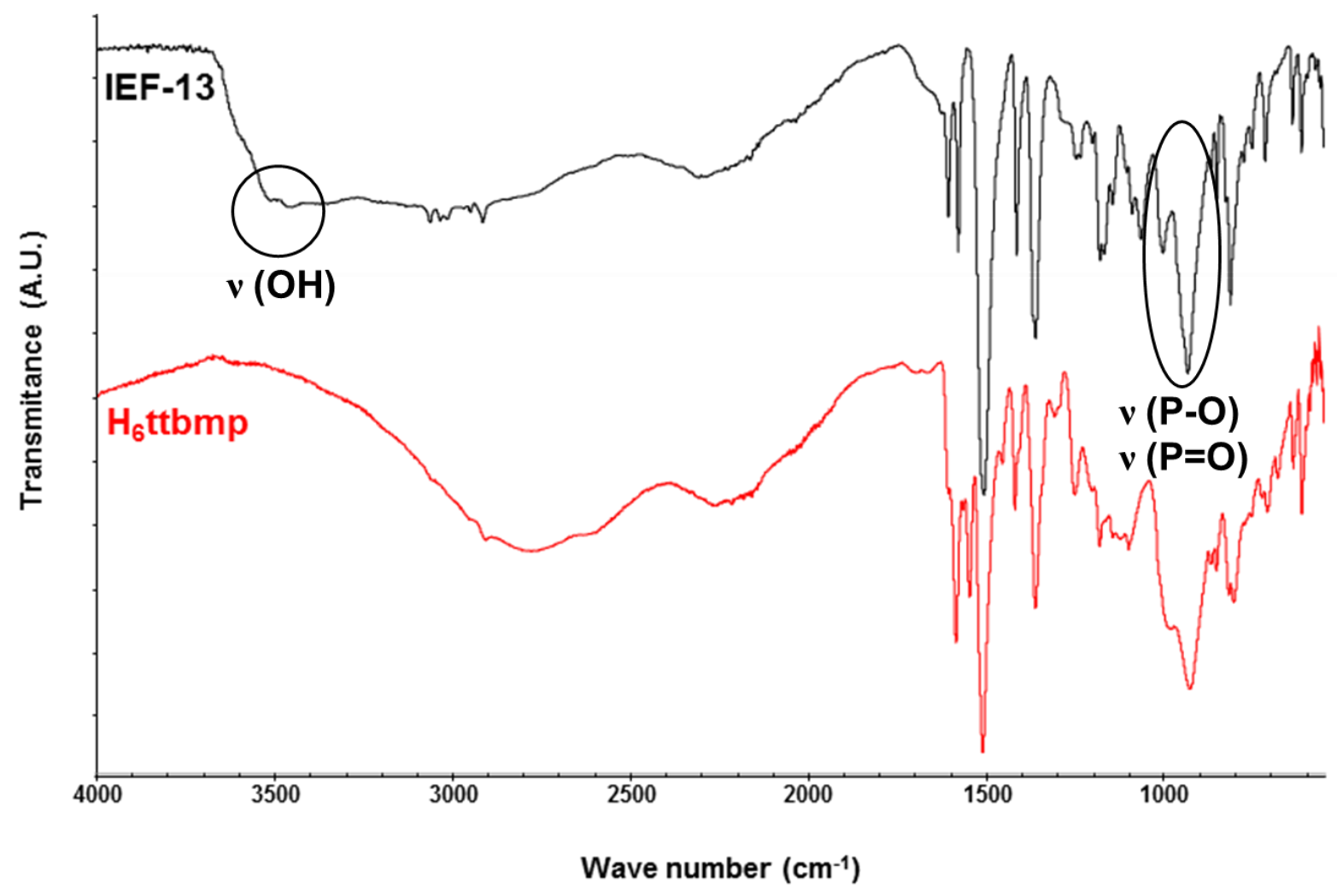

Fig. S5: FTIR spectra of the IEF-13 (black) and the linker (red). 

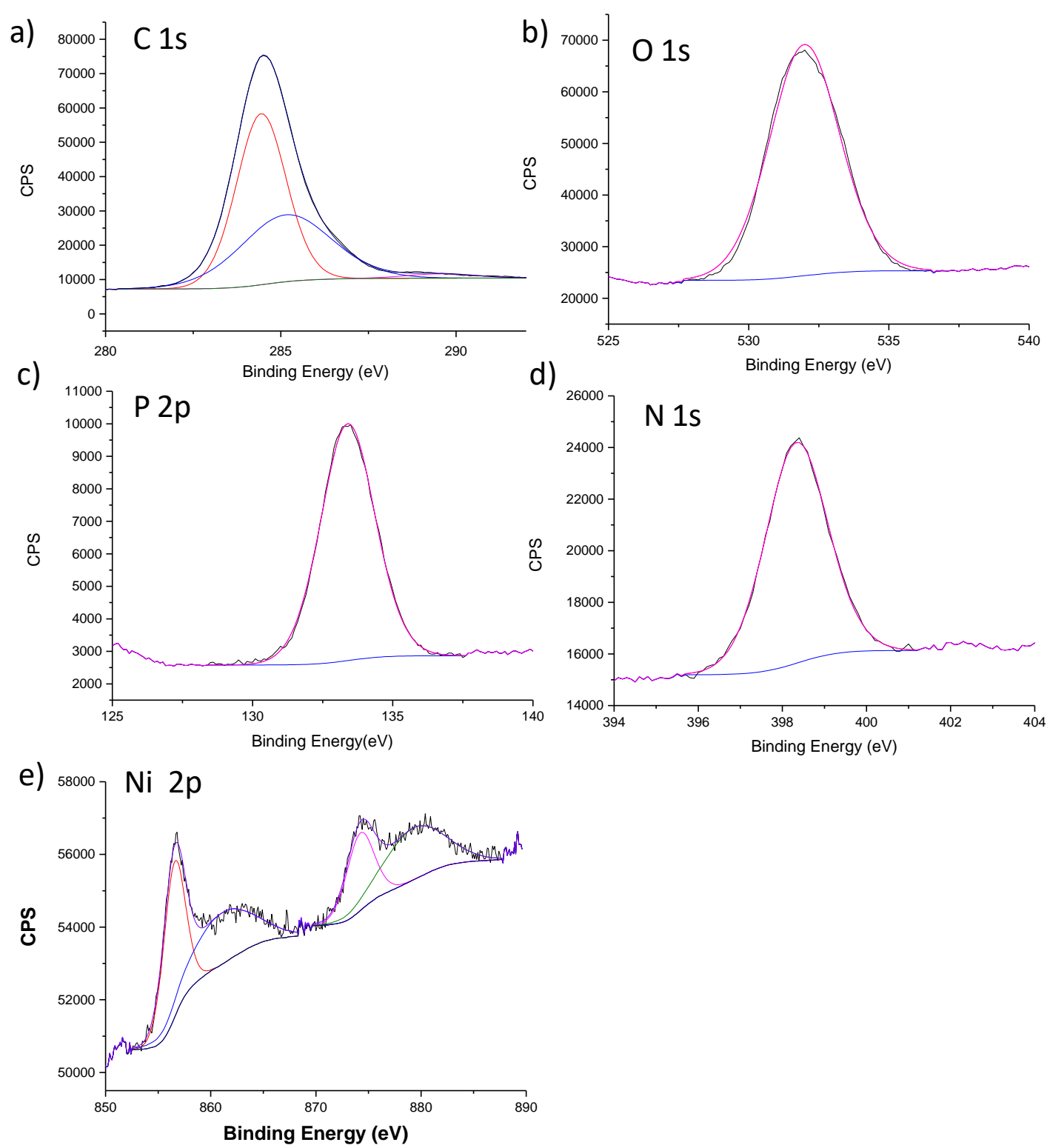

Fig. S6. XPS of individual atoms (C 1s, O 1s, P 2p, N 1s and Ni 2p) present in the IEF-13 material. 


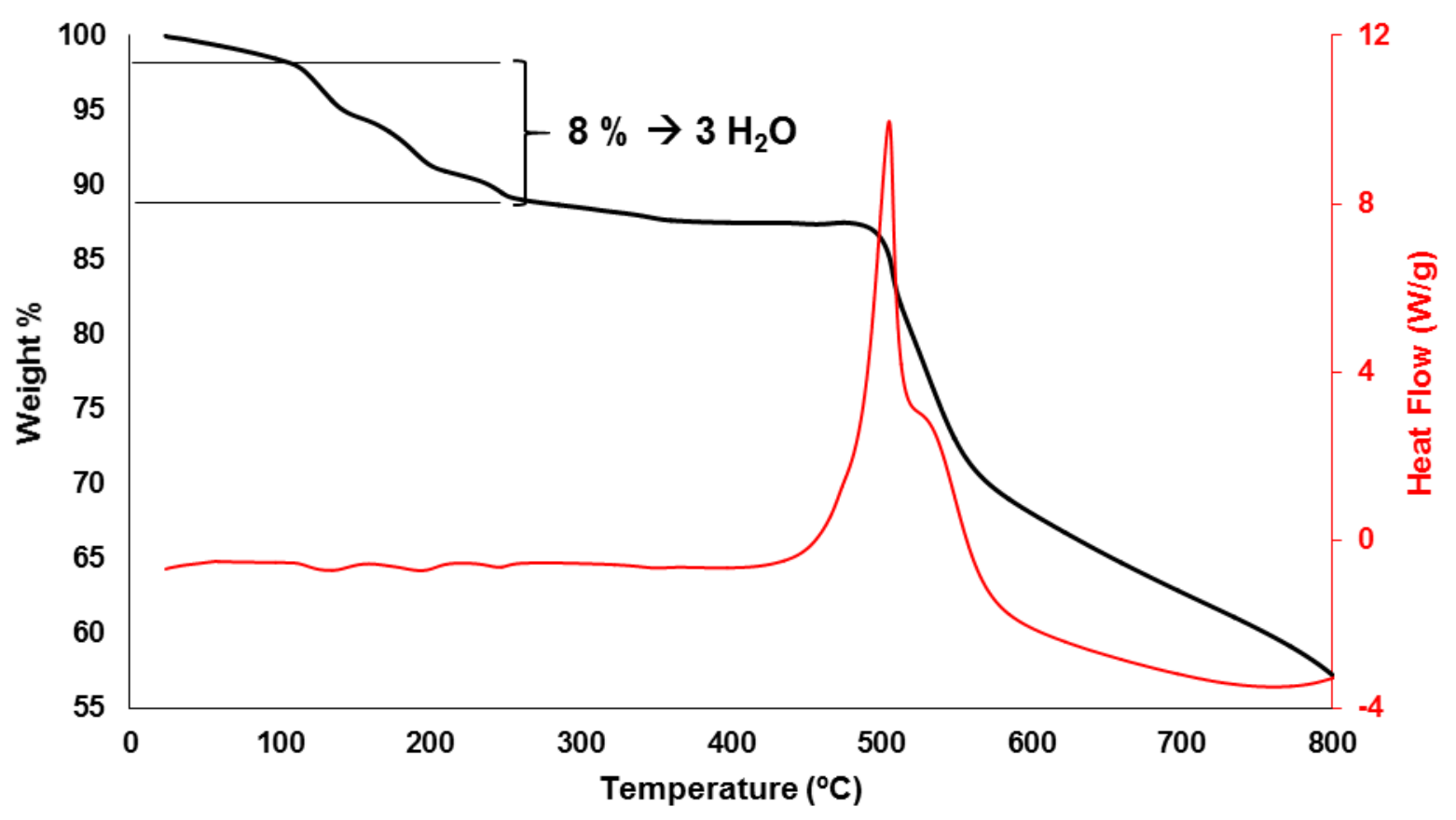

Fig. S7: TGA-DSC of the IEF-13 material.

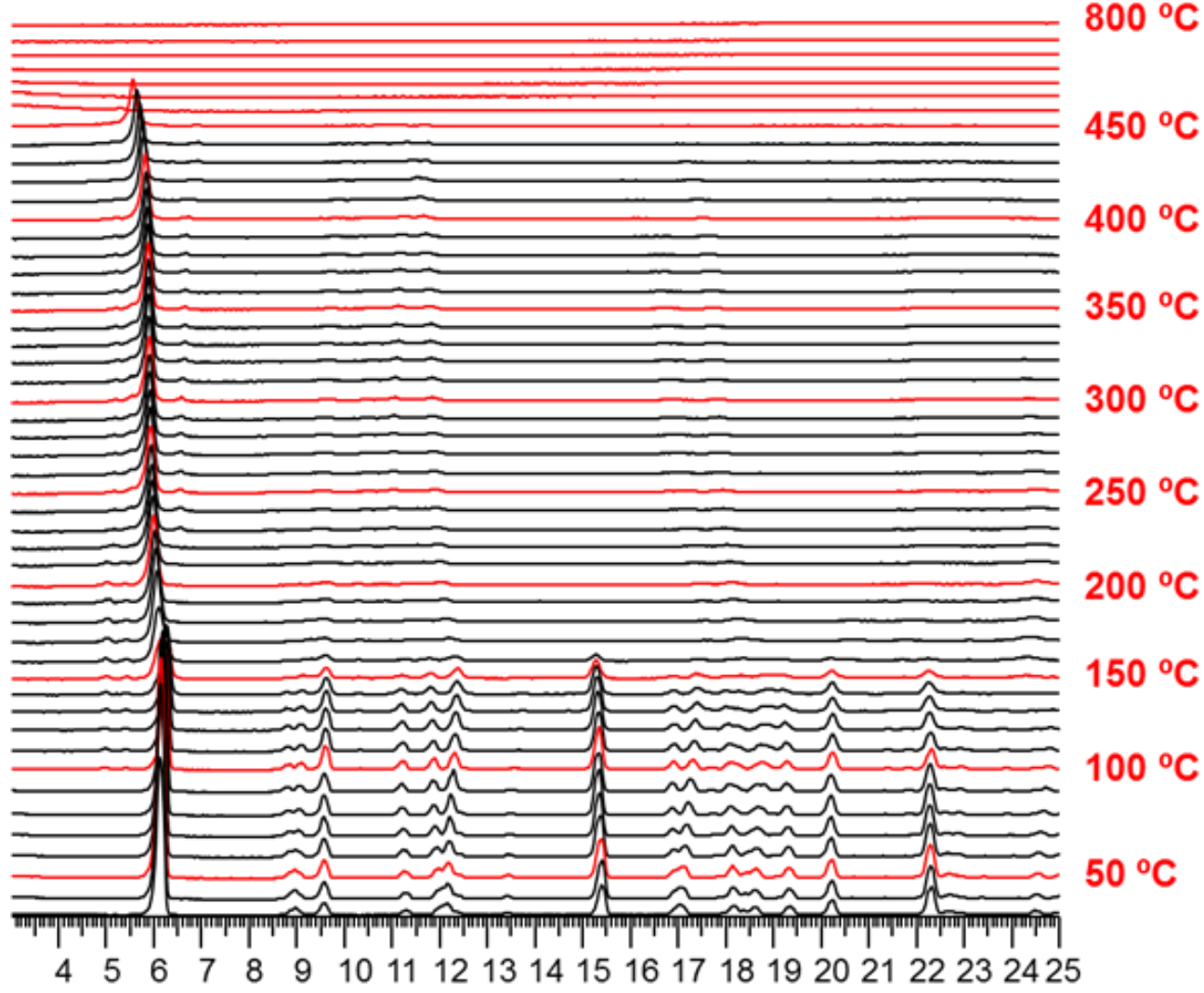

\section{$2 \theta\left({ }^{\circ}\right)$}

Fig. S8: VTPXRD of the IEF-13 material from $30{ }^{\circ} \mathrm{C}$ to $800{ }^{\circ} \mathrm{C}$ 

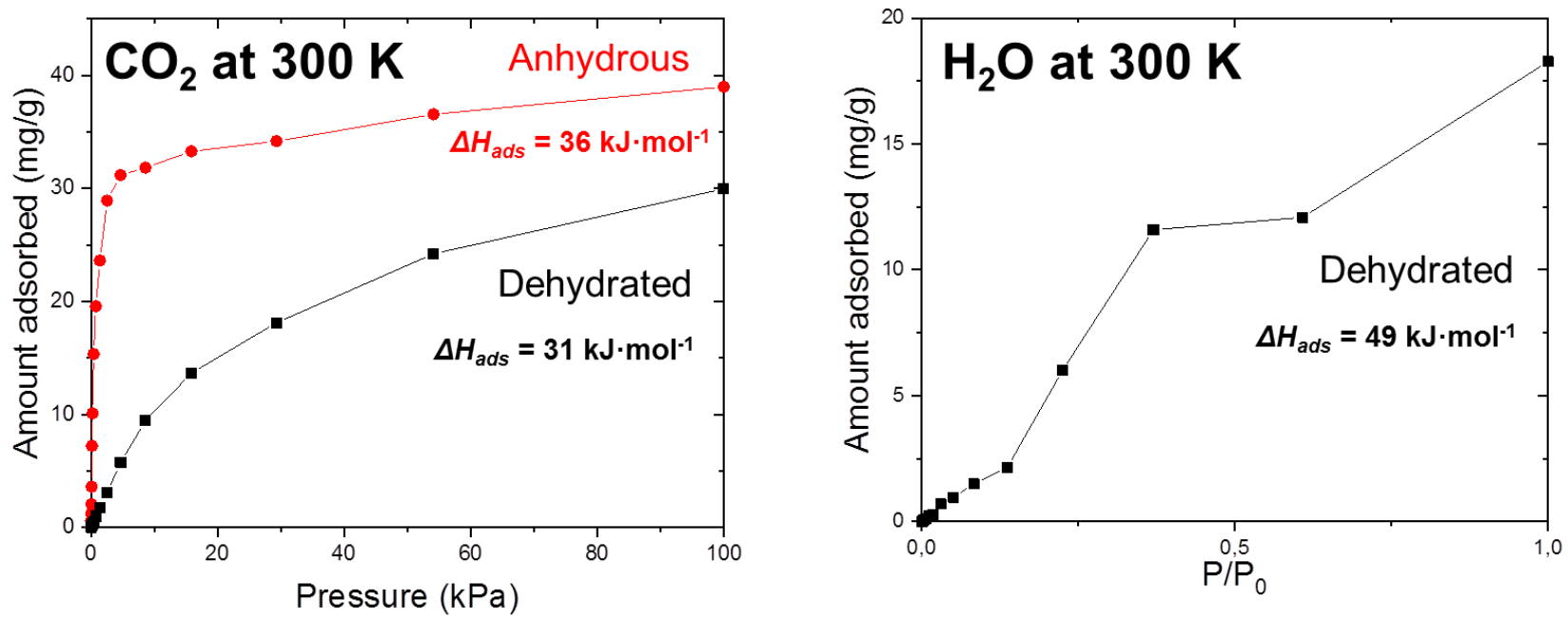

Fig. S9: Gas sorption isotherms of $\mathrm{CO}_{2}$ and $\mathrm{H}_{2} \mathrm{O}$ of the hydrated and dehydrated IEF-13 and the corresponding adsorption energies at low loading (1 molecule/cell). 

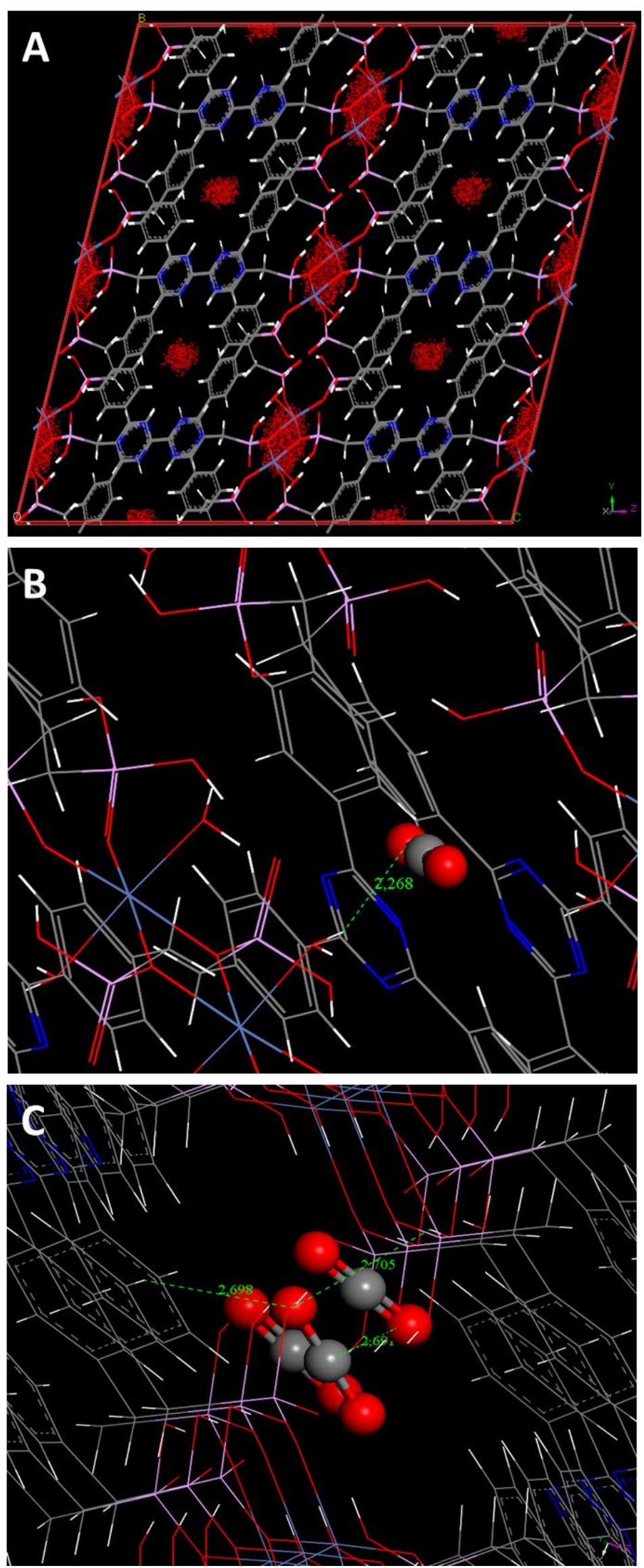

Fig. S10: Density Energy plots (A) and snapshots obtained by Grand Canonical Monte Carlo simulations for dehydrated (B) and anhydrous (C) structures for $\mathrm{CO}_{2}$. 


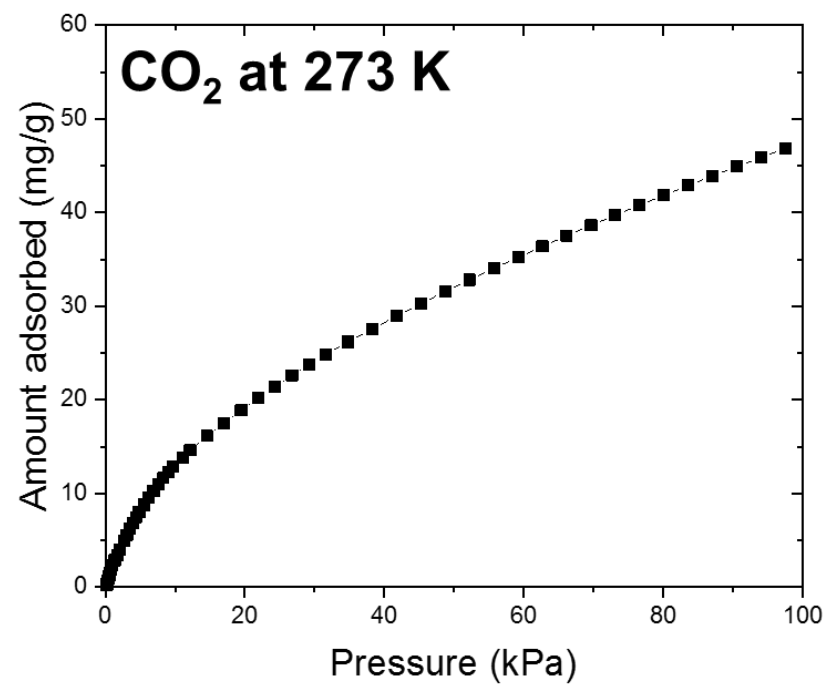

Fig. S11: $\mathrm{CO}_{2}$ sorption isotherm at $273 \mathrm{~K}$.

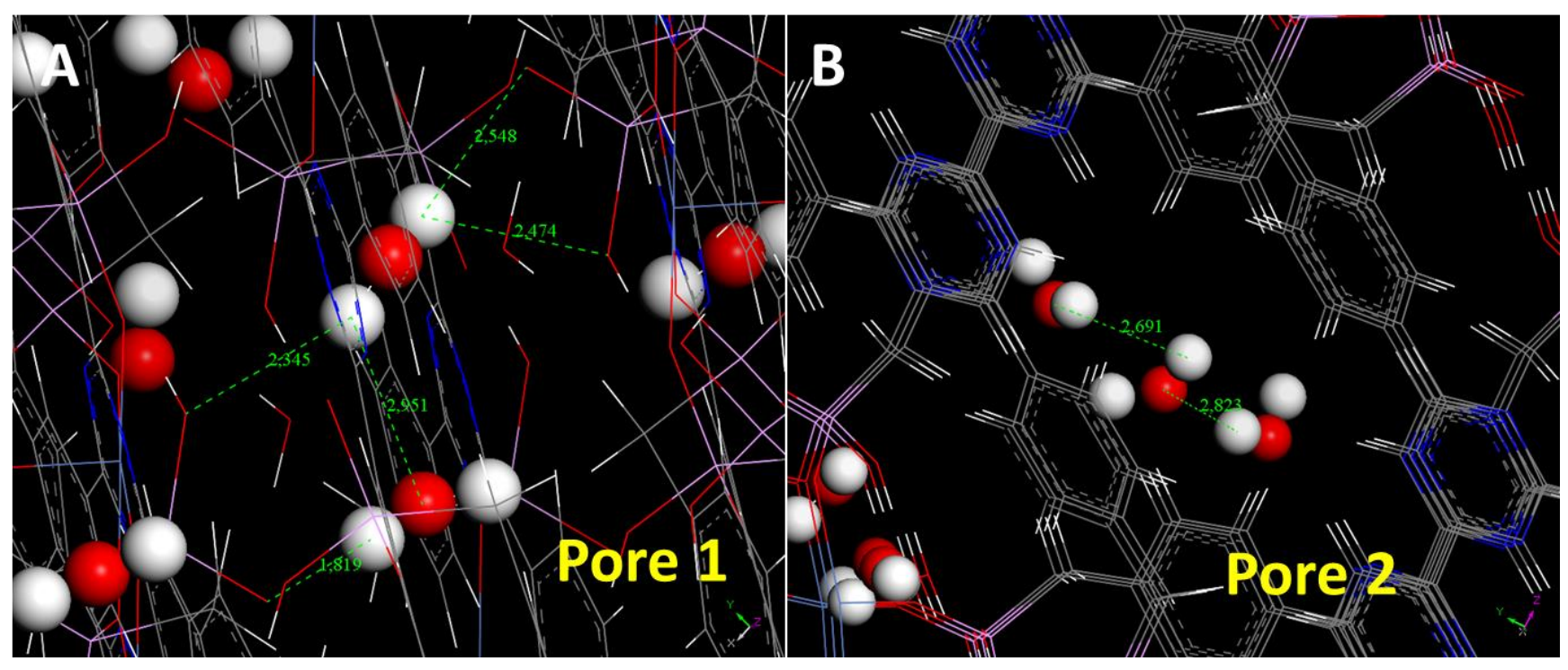

Fig. S12: Snapshots obtained by Grand Canonical Monte Carlo simulations for $\mathrm{H}_{2} \mathrm{O}$ adsorption in pore 1 (A) and pore 2 (B). 


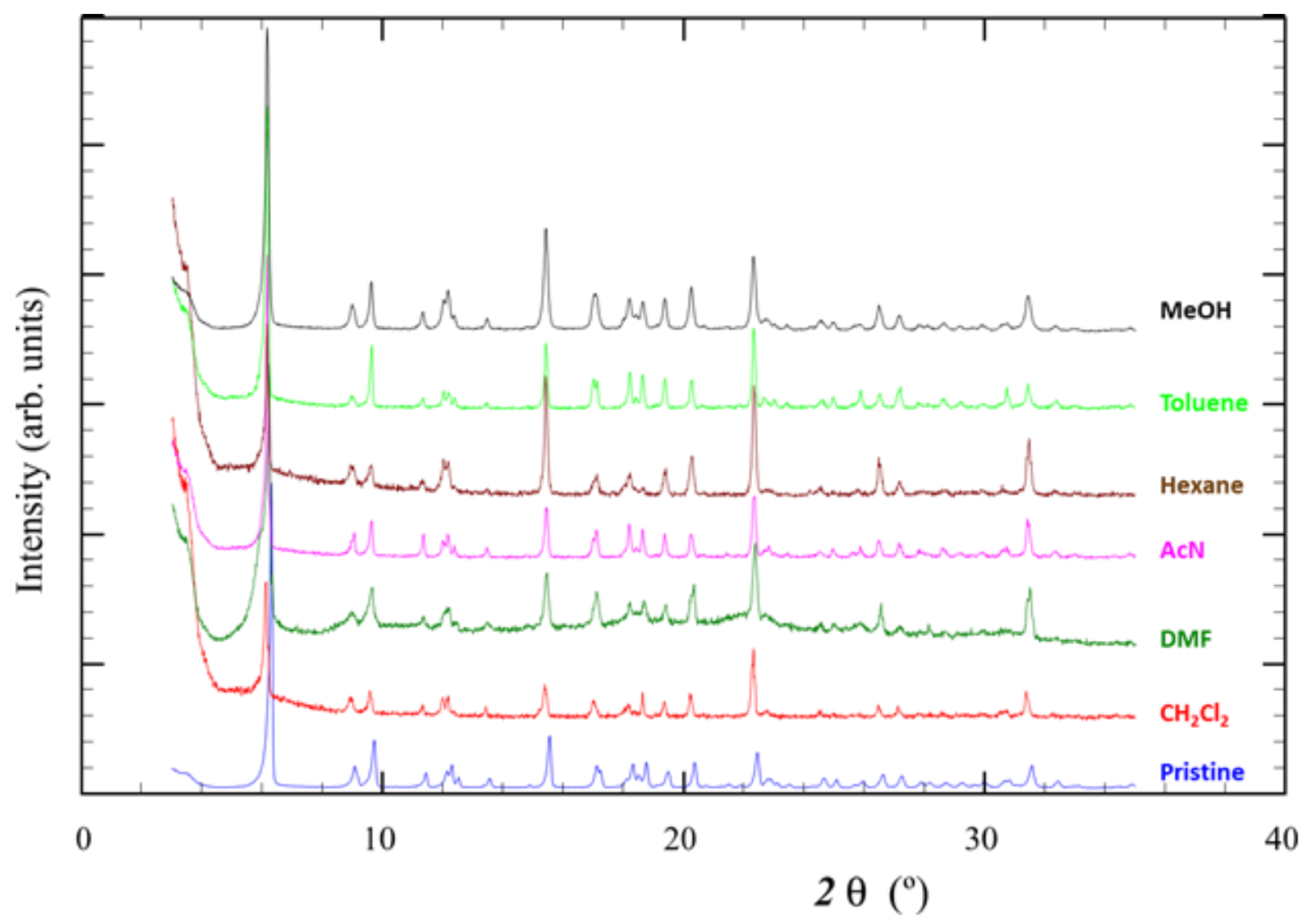

Fig. S13: PXRD patterns of the IEF-13 material after the stability test in organic media.

Note that the peak broadening observed in some solvents could be related with X-ray absorption by the solvents.

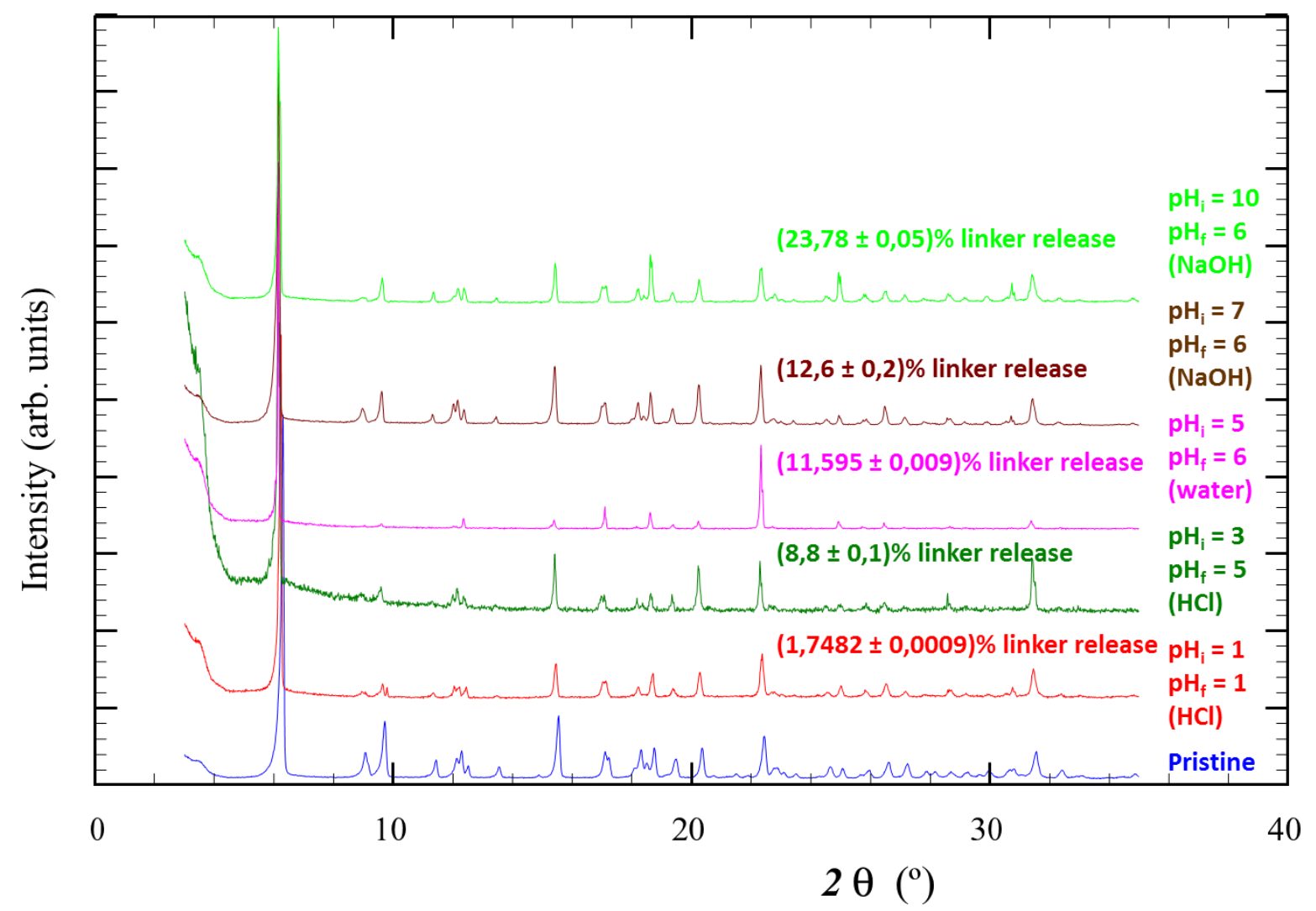

Fig. S14: PXRD patterns and degradation degree of the IEF-13 material after the stability test in aqueous media at different pH. 


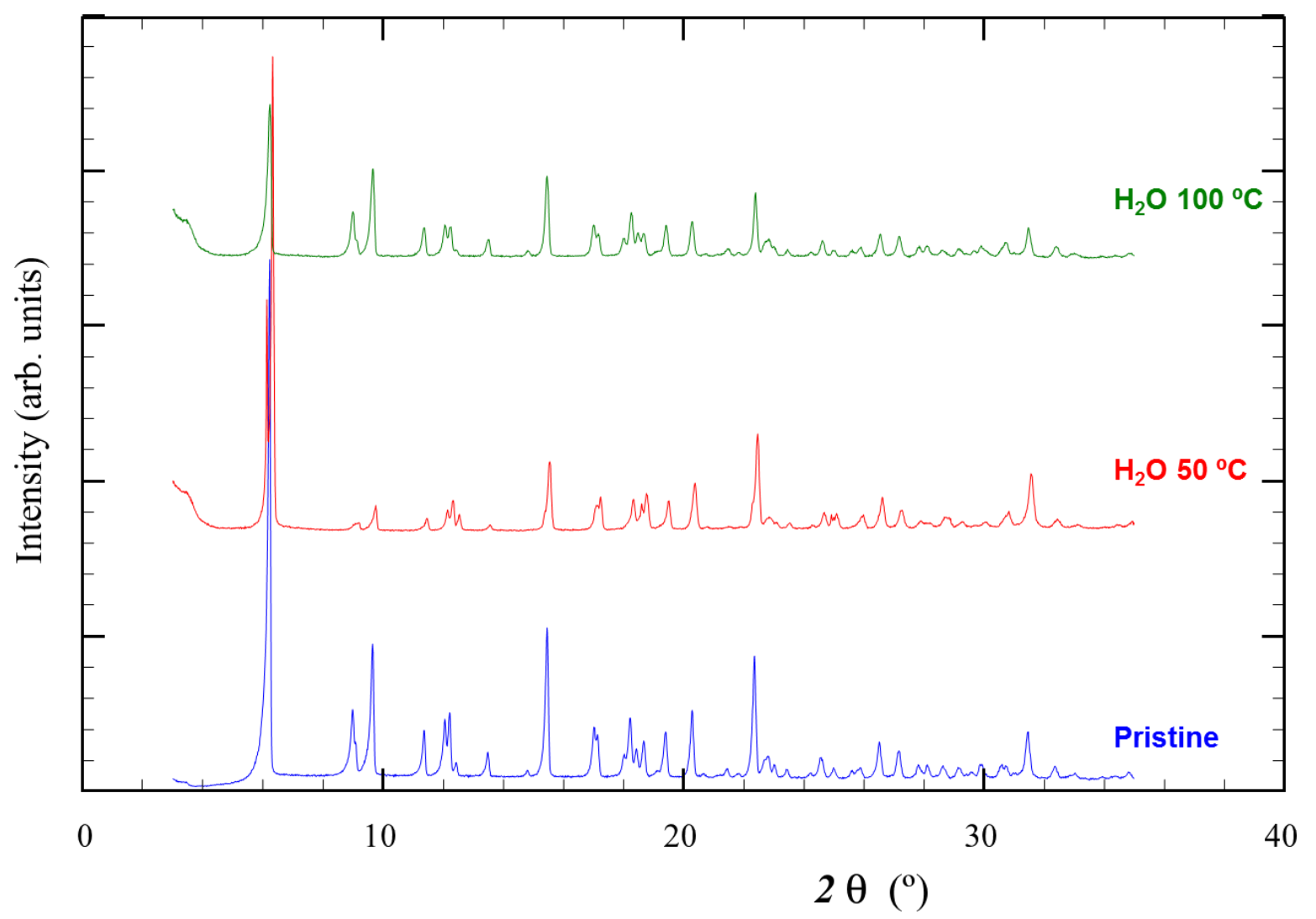

Fig. S15: PXRD patterns of the IEF-13 material after the stability test in water at different temperatures.

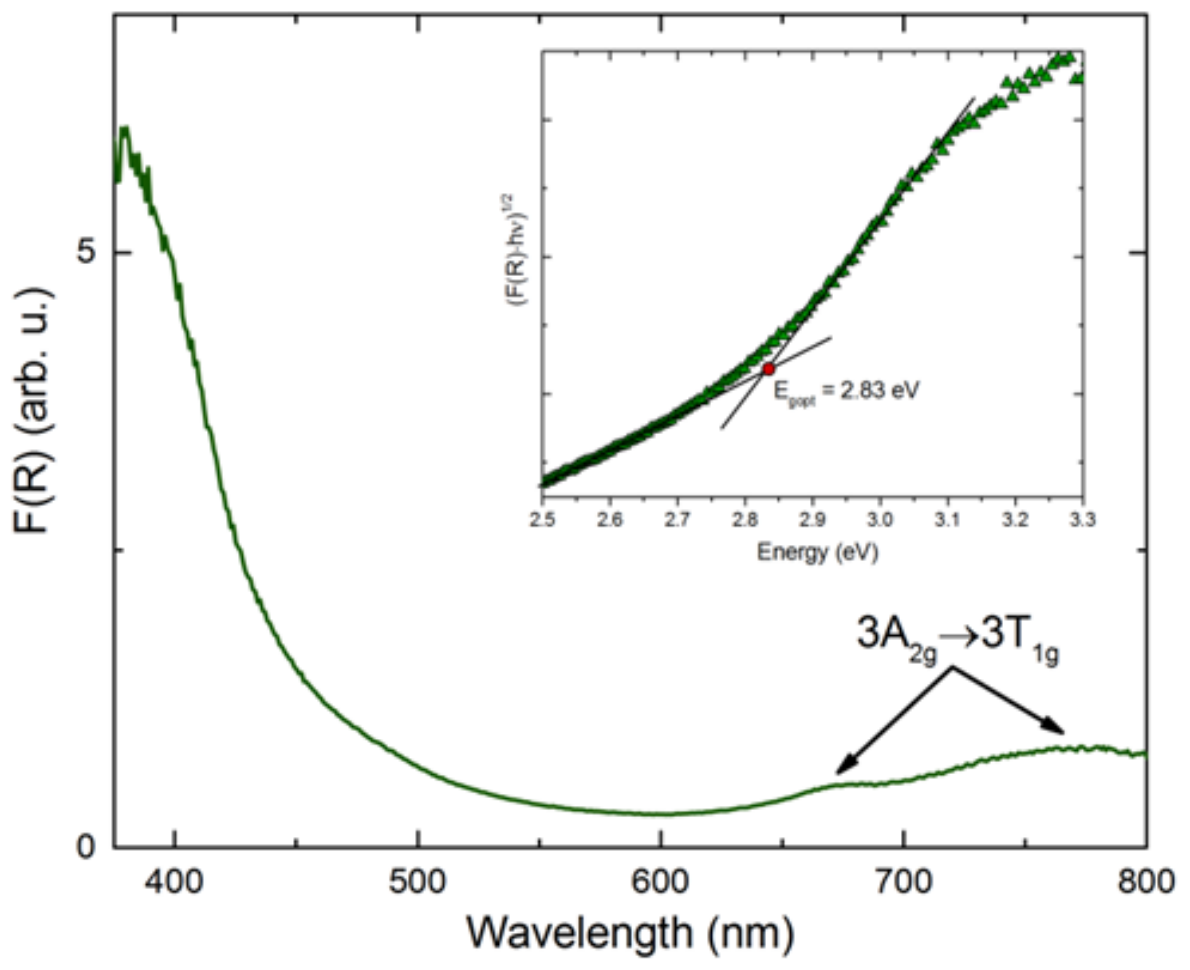

Fig. S16: Kubelka-Munk processed diffuse reflectance spectrum of IEF-13. A Tauc plot is shown as an inset 